\title{
A LOCAL-STRUCTURE-PRESERVING LOCAL DISCONTINUOUS GALERKIN METHOD FOR THE LAPLACE EQUATION*
}

\author{
FENGYAN $\mathrm{LI}^{\dagger}$ AND CHI-WANG SHU
}

\begin{abstract}
In this paper, we present a local-structure-preserving local discontinuous Galerkin (LDG) method for the Laplace equation. The method is based on the standard LDG formulation and uses piecewise harmonic polynomials, which satisfy the partial differential equation (PDE) exactly inside each element, as the approximating solutions for the primitive variable $u$, leading to a significant reduction of the degrees of freedom for the final system and hence the computational cost, without sacrificing the convergence quality of the solutions. An a priori error estimate in the energy norm is established. Numerical experiments are performed to verify optimal convergence rates of the local-structure-preserving LDG method in the energy norm and in the $L^{2}$-norm, as well as to compare it with the standard LDG method to demonstrate comparable performance of the two methods even though the new local-structure-preserving LDG method is computational less expensive.
\end{abstract}

Key words. discontinuous Galerkin method, Laplace equation, local-structure-preserving

AMS subject classifications. 65N30, 35J05

1. Introduction. It is well known that by allowing discontinuities in the finite element solution spaces, discontinuous Galerkin (DG) methods [5, 7], or the local discontinuous Galerkin (LDG) methods for partial differential equations (PDEs) containing higher than first spatial derivatives $[6,13,14,15]$, have more degrees of freedom compared with the traditional finite element methods. This is often considered as a drawback of the DG (or LDG) methods. However, these "extra" degrees of freedom may provide algorithm developers opportunities to design stable and accurate schemes by properly choosing the inter-element treatment (also called numerical fluxes). This issue has been pursued by many authors regarding different problems, see for example the review paper [7] and the special issue of the Journal of Scientific Computing on discontinuous Galerkin methods [8].

In this paper, we study a local-structure-preserving LDG method for solving the Laplace equation as a model equation, to explore another issue related to these "extra" degrees of freedom. That is, the discontinuities of the solution spaces also provide flexibility for us to choose the local solution spaces in each element, which is definitely not easy for traditional continuous finite element methods.

Our local-structure-preserving LDG method for the Laplace equation is based on the standard LDG method for elliptic equations [2]. The distinctive feature of the method is the use of harmonic polynomials (polynomials which satisfy $\triangle u=0$ ) to approximate the primitive variable $u$ in each element. In other words, the PDE is satisfied exactly in each element by the numerical solution. As a byproduct, the number of degrees of freedom for the final system is significantly reduced, therefore less computational cost is expected compared with the standard LDG method. Meanwhile, the approximation properties of the chosen spaces can guarantee no loss of the

\footnotetext{
${ }^{*}$ Received October 7, 2005; accepted for publication May 26, 2006.

$\dagger$ Department of Mathematics, University of South Carolina, Columbia, SC 29208, USA (fli@ math.sc.edu). Current address: Department of Mathematical Sciences, Rensselaer Polytechnic Institute, Troy, NY 12180, USA (lif@rpi.edu).

${ }^{\ddagger}$ Division of Applied Mathematics, Brown University, Providence, RI 02912, USA (shu@ dam.brown.edu). Research supported by ARO grant W911NF-04-1-0291, NSF grant DMS-0510345 and AFOSR grant FA9550-05-1-0123.
} 
accuracy. This local-structure-preserving idea has been successfully studied for several equations: the Maxwell equations [4] and the MHD equations [10] in which the solution spaces are locally divergence-free, and the Hamilton-Jacobi equations [11] in which the solution space is locally curl-free.

Following the approach in [2], we prove that if harmonic polynomials of degree at most $k$ are used for the primitive variable $u$, with properly chosen spaces for the auxiliary variable $\mathbf{q}=\nabla u$, the numerical solutions will give an optimal $k$-th order approximation in the energy norm (the error of $\mathbf{q}$ in $L^{2}$-norm plus terms involving the jumps of $u$ across element interfaces) for sufficiently smooth solutions. This estimate is confirmed by numerical experiments. These numerical experiments also demonstrate that the optimal $(k+1)$-th order accuracy is achieved for $u$ in the $L^{2}$-norm, though the proof of this result cannot be obtained by the direct application of the standard duality argument due to the choice of the solution spaces. This is left as an open issue to be addressed later.

Notice that the spirit of the LDG method, for which the auxiliary variable $\mathbf{q} \approx \nabla u$ can be locally eliminated, ensures us a final system with the size depending only on the dimension of the space for $u$ [2]. A simple derivation shows that the dimension of our proposed space for $u$ depends on the polynomial degree $k$ linearly, whereas the dimension of the standard choice of the LDG solution space depends on $k$ quadratically. At the same time, one can see numerically that this local-structure-preserving LDG method gives comparable results as the ones by the standard LDG method, and the condition number of the final linear system is in the same order as the one of the standard LDG method. Therefore with the reduced degrees of freedom, less computational cost is needed using this proposed method in order to achieve the same accuracy for the approximation, while certain structure of the solution is maintained exactly in each element.

The paper is organized as follows. In Section 2, we introduce the local-structurepreserving LDG method for the Laplace equation. The well-posedness of the method is established in the same section. Section 3 contains an a priori error estimate in the energy norm, which is confirmed by numerical experiments in Section 4. Also in Section 4, we include the numerical convergence study for the solution $u$ in the $L^{2}$ norm, a comparison between the results of the local-structure-preserving LDG method and the ones of the standard LDG method as well as the numerical results with an alternative choice of the space for $\mathbf{q}_{h}$. We end in Section 5 with some concluding remarks.

2. Local-structure-preserving LDG method. The following model problem is considered

$$
\begin{aligned}
-\triangle u & =0 \text { in } \Omega \\
u & =g_{D} \text { on } \Gamma_{D} \\
\frac{\partial u}{\partial n} & =\mathbf{g}_{N} \cdot \mathbf{n} \text { on } \Gamma_{N}
\end{aligned}
$$

where $\Omega \subset \mathbb{R}^{d}$ is a bounded domain with the outward unit normal $\mathbf{n}$ to its boundary $\Gamma=\Gamma_{N} \cup \Gamma_{D}$. We assume $\left|\Gamma_{D}\right|_{\mathbb{R}^{d-1}}>0$ for simplicity.

The standard LDG method for solving (2.1) would start with a triangulation $\mathcal{T}_{h}$ of the domain $\Omega$ with the element being denoted by $K$, the edge by $e$, the diameter of $K$ by $h_{K}$, and the meshsize by $h=\max _{K \in \mathcal{T}_{h}} h_{K}$. We further denote by $\mathcal{E}_{i}$ the union of all interior edges, by $\mathcal{E}_{D}$ the union of the edges on $\Gamma_{D}$, and by $\mathcal{E}_{N}$ the union of the 
edges on $\Gamma_{N}$. By introducing the auxiliary variable $\mathbf{q}=\nabla u,(2.1)$ can be rewritten as

$$
\begin{aligned}
\mathbf{q} & =\nabla u \text { in } \Omega \\
-\nabla \cdot \mathbf{q} & =0 \text { in } \Omega \\
u & =g_{D} \text { on } \Gamma_{D} \\
\mathbf{q} \cdot \mathbf{n} & =\mathbf{g}_{N} \cdot \mathbf{n} \text { on } \Gamma_{N}
\end{aligned}
$$

Following the usual definition of the LDG method for elliptic equations, see e.g. [2], we obtain the LDG method for (2.2)-(2.5): find $\left(u_{h}, \mathbf{q}_{h}\right) \in V_{h} \times \mathbf{M}_{h}$ such that $\forall K \in \mathcal{T}_{h}$,

$$
\begin{gathered}
\int_{K} \mathbf{q}_{h} \cdot \mathbf{r} d x=-\int_{K} u_{h} \nabla \cdot \mathbf{r} d x+\int_{\partial K} \hat{u}_{h} \mathbf{r} \cdot \mathbf{n}_{K} d s \\
\int_{K} \mathbf{q}_{h} \cdot \nabla v d x=\int_{\partial K} v \hat{\mathbf{q}}_{h} \cdot \mathbf{n}_{K} d s .
\end{gathered}
$$

Here $\mathbf{n}_{K}$ is the outward unit normal vector of $\partial K$. There are two things to be specified in order to finalize the method. One is to choose the numerical fluxes: $\hat{u}_{h}$ and $\hat{\mathbf{q}}_{h}$, which we take as in [2]

$$
\begin{aligned}
& \hat{\mathbf{q}}=\{\{\mathbf{q}\}\}-C_{11} \llbracket u \rrbracket-\mathbf{C}_{12} \llbracket \mathbf{q} \rrbracket \\
& \hat{u}=\quad\{\{u\}\}+\mathbf{C}_{12} \cdot \llbracket u \rrbracket
\end{aligned}
$$

for any interior edge $e$, and

$$
\begin{aligned}
& \hat{\mathbf{q}}:= \begin{cases}\mathbf{q}^{+}-C_{11}\left(u^{+} \mathbf{n}^{+}+g_{D} \mathbf{n}^{-}\right) & \text {on } \Gamma_{D} \\
\mathbf{g}_{N} & \text { on } \Gamma_{N}\end{cases} \\
& \hat{u}:= \begin{cases}g_{D} & \text { on } \Gamma_{D} \\
u^{+} & \text {on } \Gamma_{N}\end{cases}
\end{aligned}
$$

for edges on the domain boundary. Here the average $\{\{\cdot\}\}$ and the jump $\llbracket \cdot \rrbracket$ are defined as follows: at any point $x \in e \in \mathcal{E}_{i}$,

$$
\begin{gathered}
\{\{u\}\}:=\left(u^{+}+u^{-}\right) / 2, \quad\{\{\mathbf{q}\}\}:=\left(\mathbf{q}^{+}+\mathbf{q}^{-}\right) / 2 \\
\llbracket u \rrbracket:=\left(u^{+} \mathbf{n}^{+}+u^{-} \mathbf{n}^{-}\right) / 2, \quad \llbracket \mathbf{q} \rrbracket:=\left(\mathbf{q}^{+} \cdot \mathbf{n}^{+}+\mathbf{q}^{-} \cdot \mathbf{n}^{-}\right) / 2,
\end{gathered}
$$

with the following meanings of the notations: suppose $e=K^{+} \cap K^{-}$, let $\mathbf{n}^{+}$and $\mathbf{n}^{-}$be the outer unit normals of $K^{+}$and $K^{-}$along $e$ respectively, and $\left(u^{+}, \mathbf{q}^{+}\right)$(respectively $\left.\left(u^{-}, \mathbf{q}^{-}\right)\right)$be the trace of the piecewise smooth function $(u, \mathbf{q})$ inside $K^{+}$(respectively $K^{-}$) along $e$. For a boundary edge $e \subset K$, we denote $K^{+}=K$ and $\mathbf{n}^{+}$is the outer unit normal along $\partial \Omega$. The parameters $C_{11}$ and $C_{12}$ in general depend on $x \in e$, and we will comment on the choice of these parameters later.

To complete the scheme, the second component is to choose the solution spaces $V_{h}$ and $\mathbf{M}_{h}$. The standard choice of these spaces is [2]

$$
\begin{gathered}
\bar{V}_{h}:=\bar{V}_{h}^{k}=\left\{u \in L^{2}(\Omega):\left.u\right|_{K} \in P^{k}(K), \forall K \in \mathcal{T}_{h}\right\}, \\
\overline{\mathbf{M}}_{h}:=\overline{\mathbf{M}}_{h}^{k}=\left\{\mathbf{q} \in\left[L^{2}(\Omega)\right]^{d}:\left.\mathbf{q}\right|_{K} \in\left[P^{k}(K)\right]^{d}, \forall K \in \mathcal{T}_{h}\right\},
\end{gathered}
$$


TABle 2.1

The dimensions of the local-structure-preserving space $\left.V_{h}^{k}\right|_{K}$ and the standard space $\left.\bar{V}_{h}^{k}\right|_{K}$ in each element.

\begin{tabular}{c|ccccccc}
\hline \hline $\mathrm{k}$ & 1 & 2 & 3 & 4 & 5 & 6 & 7 \\
\hline $\operatorname{dim}\left(\left.V_{h}^{k}\right|_{K}\right)$ & 3 & 5 & 7 & 9 & 11 & 13 & 15 \\
\hline $\operatorname{dim}\left(\left.V_{h}^{k}\right|_{K}\right)$ & 3 & 6 & 10 & 15 & 21 & 28 & 36 \\
\hline \hline
\end{tabular}

where $P^{k}(K)$ denotes the space of polynomials in $\mathrm{K}$ of degree at most $k$. In this paper, we would like to propose a different choice of the solution spaces

$$
\begin{gathered}
V_{h}:=V_{h}^{k}=\left\{u \in L^{2}(\Omega):\left.u\right|_{K} \in P^{k}(K),\left.\triangle u\right|_{K}=0, \forall K \in \mathcal{T}_{h}\right\}, \\
\mathbf{M}_{h}:=\mathbf{M}_{h}^{k}=\left\{\mathbf{q} \in\left[L^{2}(\Omega)\right]^{d}:\left.\mathbf{q}\right|_{K} \in\left[P^{k}(K)\right]^{d},\left.\nabla \cdot \mathbf{q}\right|_{K}=0, \forall K \in \mathcal{T}_{h}\right\} .
\end{gathered}
$$

Notice the piecewise harmonic polynomials are used as the approximations for $u$. It is easy to write a local basis of $\left.V_{h}^{k}\right|_{K}$. For example, if we take $K=\left[-\frac{1}{2}, \frac{1}{2}\right] \times\left[-\frac{1}{2}, \frac{1}{2}\right] \subset \mathbb{R}^{2}$, one choice of the basis of $\left.V_{h}^{k}\right|_{K}$ could be:

$k=1: 1, x, y$

$k=2:$ add $x^{2}-y^{2}, x y$

$k=3:$ add $x^{3}-3 x y^{2}, y^{3}-3 x^{2} y$

$k=4:$ add $x^{4}-6 x^{2} y^{2}+y^{4}, x^{3} y-x y^{3}$

\section{REMARK 2.1.}

- Using the piecewise harmonic polynomials $(\triangle u=0)$ for $u_{h}$, the PDE is satisfied exactly in each element by the approximating solutions.

- Due to the choice of the numerical fluxes (2.8)-(2.11), the function $\mathbf{q}_{h}$ can be locally solved in terms of $u_{h}$ from (2.6) and eliminated from the equations, hence the size of the final system to be solved only depends on the size of the solution space for $u_{h}$. This is the reason that the method is called a local discontinuous Galerkin method in [6].

- Notice that the dimension of this local-structure-preserving space $\left.V_{h}^{k}\right|_{K}$ for $u_{h}$ is $2 k+1$, which depends on $k$ linearly, whereas the dimension of the standard choice of the space $\left.\bar{V}_{h}^{k}\right|_{K}$ for $u_{h}$ is $(k+2)(k+1) / 2$, which depends on $k$ quadratically. In other words, using the proposed space will significantly reduce the degrees of freedom of the final system especially for large $k$. In Table 2.1, we display the dimensions of these two spaces for some values of the polynomial degree $k$.

- Besides the consideration on the approximating properties of the discrete spaces $V_{h}$ and $\mathbf{M}_{h}$, there is one more condition needed on these spaces which ensures the well-posedness of the scheme (see Lemma 2.2) and the error estimate (see Theorem 3.1); that is

$$
\nabla V_{h} \subset \mathbf{M}_{h}
$$

From (2.14), one can see that there are some alternative choices for $\mathbf{M}_{h}$ :

$$
\mathbf{M}_{h}=\overline{\mathbf{M}}_{h}^{k}, \quad \text { or } \mathbf{M}_{h}=\overline{\mathbf{M}}_{h}^{k-1}
$$

We will further comment on these choices in Remark 3.6. 
- The coefficient $C_{11}$ needs to be positive for the well-posedness of the scheme (Lemma 2.2). Throughout this paper, $C_{12}$ is taken to be $O(1)$. In the numerical experiments, we take $C_{12}$ to be along the (pre-chosen) direction of the normal vector of each edge with the modulus $1 / 2$. By doing so, if $C_{11}=0$ in (2.8)(2.11), the numerical fluxes become the "alternating fluxes" $(\hat{u}, \hat{\mathbf{q}})=\left(u^{+}, \mathbf{q}^{-}\right)$, or $=\left(u^{-}, \mathbf{q}^{+}\right)$, which simplify the computation and make the stencil narrower when the auxiliary variable $\mathbf{q}$ is locally eliminated. Such "alternating fluxes" have been used extensively in time-dependent problems [6, 14, 15, 13] with great success.

By summing up over all $K \in \mathcal{T}_{h}$, the method can be written as: find $\left(u_{h}, \mathbf{q}_{h}\right) \in$ $V_{h} \times \mathbf{M}_{h}$, such that

$$
\begin{aligned}
a\left(\mathbf{q}_{h}, \mathbf{r}\right)+b\left(u_{h}, \mathbf{r}\right) & =F(\mathbf{r}) \quad \forall \mathbf{r} \in \mathbf{M}_{h} \\
-b\left(v, \mathbf{q}_{h}\right)+c\left(u_{h}, v\right) & =G(v) \quad \forall v \in V_{h}
\end{aligned}
$$

where

$$
\begin{aligned}
a(\mathbf{q}, \mathbf{r}) & =\int_{\Omega} \mathbf{q} \cdot \mathbf{r} d x \\
b(u, \mathbf{r}) & =\sum_{K \in \mathcal{T}_{h}} \int_{K} u \nabla \cdot \mathbf{r} d x-\int_{\mathcal{E}_{i}}\left(\{\{u\}\}+\mathbf{C}_{12} \cdot \llbracket u \rrbracket\right) \llbracket \mathbf{r} \rrbracket d s-\int_{\mathcal{E}_{N}} u \mathbf{r} \cdot \mathbf{n} d s \\
& =-\sum_{K \in \mathcal{T}_{h}} \int_{K} \nabla u \cdot \mathbf{r} d x+\int_{\mathcal{E}_{i}}\left(\{\{\mathbf{r}\}\}-\mathbf{C}_{\mathbf{1 2}} \llbracket \mathbf{r} \rrbracket\right) \cdot \llbracket u \rrbracket d s+\int_{\mathcal{E}_{D}} u \mathbf{r} \cdot \mathbf{n} d s \\
c(u, v) & =\int_{\mathcal{E}_{i}} C_{11} \llbracket u \rrbracket \cdot \llbracket v \rrbracket d s+\int_{\mathcal{E}_{D}} C_{11} u v d s \\
F(\mathbf{r}) & =\int_{\mathcal{E}_{D}} g_{D} \mathbf{r} \cdot \mathbf{n} d s, \quad G(v)=\int_{\mathcal{E}_{D}} C_{11} g_{D} v d s+\int_{\mathcal{E}_{N}} v \mathbf{g}_{\mathbf{N}} \cdot \mathbf{n} d s .
\end{aligned}
$$

A more compact way of writing the scheme is to find $\left(u_{h}, \mathbf{q}_{h}\right) \in V_{h} \times \mathbf{M}_{h}$, which satisfies

$$
\mathcal{A}\left(\mathbf{q}_{h}, u_{h} ; \mathbf{r}, v\right)=\mathcal{F}(\mathbf{r}, v) \quad \forall(v, \mathbf{r}) \in V_{h} \times \mathbf{M}_{h}
$$

where

$$
\mathcal{A}(\mathbf{q}, u ; \mathbf{r}, v)=a(\mathbf{q}, \mathbf{r})+b(u, \mathbf{r})-b(v, \mathbf{q})+c(u, v), \quad \mathcal{F}(\mathbf{r}, v)=F(\mathbf{r})+G(v) .
$$

Lemma 2.2 (Well-posedness). The LDG method defined by (2.17) with $C_{11}>0$ provides a unique approximation solution $\left(u_{h}, \mathbf{q}_{h}\right) \in V_{h} \times \mathbf{M}_{h}$.

Proof. Exactly the same argument as that in the Proposition 2.1 in [2] can be used here, since the condition (2.14) is the only property of $V_{h}$ and $\mathbf{M}_{h}$ needed in the proof. $\mathrm{Q}$

3. An a priori error estimate in the energy norm. In this section, we present an a priori error estimate in the energy norm for the scheme (2.17). We follow a similar argument as that in [2]. Since what we emphasize in this paper is the local-structure-preserving idea, we assume the full elliptic regularity in this section for simplicity. That is, the exact solution $(u, \mathbf{q}) \in V \times \mathbf{M}$, where

$$
V:=\left\{u \in H^{s+2}(\Omega): \triangle u=0 \text { in } \Omega\right\} \quad \mathbf{M}:=\left\{\mathbf{q} \in\left[H^{s+1}(\Omega)\right]^{d}: \nabla \cdot \mathbf{q}=0 \text { in } \Omega\right\}, \quad s \geq 0 .
$$


The general cases can be obtained by more delicate analysis. We further assume the triangulations $\mathcal{T}_{h}$ are regular; that is, there exists a positive constant $\sigma$ independent of $h$ such that

$$
\frac{h_{K}}{\rho_{K}} \leq \sigma, \quad \forall K \in \mathcal{T}_{h} .
$$

Here $\rho_{K}$ is the diameter of the biggest ball $B_{K}$ included in $K$. And $K$ is star-shaped with respect to $B_{K}$.

Theorem 3.1 (Error estimate in the energy norm). Let $(u, \mathbf{q}) \in V \times \mathbf{M}$ be the exact solution of (2.1) and $\left(u_{h}, \mathbf{q}_{h}\right) \in V_{h}^{k} \times \mathbf{M}_{h}^{k}$ be the approximate local-structurepreserving $L D G$ solution of (2.17). For $C_{12}=O(1)$, we have

$$
\left|\left(\mathbf{q}-\mathbf{q}_{h}, u-u_{h}\right)\right|_{\mathcal{A}} \leq C h^{P}\|u\|_{s+2},
$$

where

$$
\begin{aligned}
|(\mathbf{q}, u)|_{\mathcal{A}} & =\left(\|\mathbf{q}\|_{0}^{2}+\int_{\mathcal{E}_{i}} C_{11}|\llbracket u \rrbracket|^{2} d s+\int_{\mathcal{E}_{D}} C_{11} u^{2} d s\right)^{1 / 2} \\
P & = \begin{cases}\min \left\{s+\frac{1}{2}, k\right\} & C_{11} \sim O(1) \\
\min \{s+1, k\} & C_{11} \sim O\left(h^{-1}\right) .\end{cases}
\end{aligned}
$$

Here the constant $C$ depends on $\Omega, d$, s and $\sigma$.

There are mainly two ingredients in the proof. One is the Galerkin orthogonality from the consistency of the scheme:

$$
\mathcal{A}\left(\mathbf{q}-\mathbf{q}_{h}, u-u_{h} ; \mathbf{r}, v\right)=0, \quad \forall(v, \mathbf{r}) \in V_{h} \times \mathbf{M}_{h} .
$$

The other is the approximation property of the solution spaces $V_{h}$ and $\mathbf{M}_{h}$.

LEMma 3.2 (Approximation property of $V_{h}$ and $\mathbf{M}_{h}$ : I). There exists a constant $C=C(s, d, \sigma)$, such that $\forall(w, \mathbf{r}) \in V \times \mathbf{M}$, there exist $\left(w_{h}, \mathbf{r}_{h}\right) \in V_{h}^{k} \times \mathbf{M}_{h}^{k}$ satisfying

$$
\left\|w-w_{h}\right\|_{0, K} \leq C h_{K}^{\min \{s+1, k\}+1}|w|_{s+2, K}, \quad\left|w-w_{h}\right|_{1, K} \leq C h_{K}^{\min \{s+1, k\}}|w|_{s+2, K}
$$$$
\left\|\mathbf{r}-\mathbf{r}_{h}\right\|_{0, K} \leq C h_{K}^{\min \{s, k\}+1}|\mathbf{r}|_{s+1, K}
$$

Proof. First we assume $s$ is an integer. (3.7) is a part of the results of Theorem 4.3 in [1]. (3.6) can be obtained by following the proofs of Theorems 4.1, 4.2 and 4.3 in [1] line by line with the following modification in the proof of Theorems 4.2 and 4.3: Notationwise, we regard $D$ in the proof as our $K$ and we let $B$ and $S$ in the proof be the same; We start with a scaler function $\left.v \in V\right|_{K}$ instead of a vector $\mathbf{v} \in \mathbf{S}^{m}(D)$ and all the functions involved are scaler as well; We replace the divergence operator "div" by the Laplace operator " $\triangle$ " (this operator appears at the very end of these two proofs). The Interpolation Theorem (see Theorem 1.4 in [9]) can give the results for general $s \geq 0$.

With the same notations as in Lemma 3.2, if we introduce $\boldsymbol{\Pi}$ as the $L^{2}$ projection from $\mathbf{M}$ onto $\mathbf{M}_{h}$, we further have the following results: 
COROLlaRY 3.3 (Approximation property of $V_{h}$ and $\mathbf{M}_{h}$ : II).

$$
\begin{aligned}
\left\|w-w_{h}\right\|_{0, \partial K} & \leq C h_{K}^{\min \{s+1, k\}+1 / 2}|w|_{s+2, K} \\
\|\mathbf{r}-\boldsymbol{\Pi r}\|_{0, K} & \leq C h_{K}^{\min \{s, k\}+1}|\mathbf{r}|_{s+1, K} \\
\|(\mathbf{r}-\mathbf{\Pi r}) \cdot \mathbf{n}\|_{0, \partial K} & \leq C h_{K}^{\min \{s, k\}+1 / 2}|\mathbf{r}|_{s+1, K}
\end{aligned}
$$

Proof. (3.8) holds because of (3.6) and $|v|_{0, \partial K}^{2} \leq C\left\{h_{K}^{-1}\|v\|_{0, K}^{2}+\|v\|_{0, K}|v|_{1, K}\right\}$ for $v \in H^{1}(K)$. We get (3.9) because of $\|\mathbf{r}-\boldsymbol{\Pi r}\|_{0, K}=\inf _{\mathbf{r}_{h} \in \mathbf{M}_{h}}\left\|\mathbf{r}-\mathbf{r}_{h}\right\|_{0, K}$ and (3.7). Notice $\left.\nabla \cdot(\mathbf{r}-\boldsymbol{\Pi r})\right|_{K}=0,(3.9)$ and the trace theorem with the scaling for $\mathbf{p} \in H(\operatorname{div}, K)[12]:\|\mathbf{p} \cdot \mathbf{n}\|_{0, \partial K} \leq C\left(h_{K}^{-1}\|\mathbf{p}\|_{0, K}^{2}+\|\nabla \cdot \mathbf{p}\|_{0, K}^{2}\right)^{1 / 2}$ lead to (3.10).

The following inverse inequality (see [3]) and a key inequality related to the integral of the average / jump functions will also be needed in the proof:

Lemma 3.4 (Inverse inequality). For $w \in P^{k}(K)$, we have

$$
\|w\|_{0, \partial K} \leq C h_{K}^{-1 / 2}\|w\|_{0, K}
$$

LEMma 3.5 (Inequality related to the average and jump functions). If $e=$ $K^{+} \cap K^{-}$, with the notations defined by (2.12) and (2.13), we have

$$
\int_{e}\left(\{\{\mathbf{a}\}\}-\mathbf{C}_{12} \llbracket \mathbf{a} \rrbracket\right) \cdot \llbracket b \rrbracket d s \leq C\left(\sum_{K \in K^{+} \cup K^{-}} \frac{1}{C_{11}}\left\|\mathbf{a} \cdot \mathbf{n}_{K}\right\|_{0, \partial K}^{2}\right)^{1 / 2}\left(\int_{e} C_{11}|\llbracket b \rrbracket|^{2} d s\right)^{1 / 2}
$$

where the constant $C$ depends on $\mathbf{C}_{12}$.

Proof. By definition

$$
\begin{aligned}
& \int_{e}\left(\{\{\mathbf{a}\}\}-\mathbf{C}_{12} \llbracket \mathbf{a} \rrbracket\right) \cdot \llbracket b \rrbracket d s \\
& =\int_{e}\left(\frac{\mathbf{a}^{+}+\mathbf{a}^{-}}{2}-\mathbf{C}_{12}\left(\mathbf{a}^{+} \cdot \mathbf{n}^{+}+\mathbf{a}^{-} \cdot \mathbf{n}^{-}\right)\right) \cdot\left(b^{+} \mathbf{n}^{+}+b^{-} \mathbf{n}^{-}\right) d s \\
& =\int_{e}\left(\frac{\left(\mathbf{a}^{+} \cdot \mathbf{n}^{+}\right) \mathbf{n}^{+}+\left(\mathbf{a}^{-} \cdot \mathbf{n}^{-}\right) \mathbf{n}^{-}}{2}-\mathbf{C}_{12}\left(\mathbf{a}^{+} \cdot \mathbf{n}^{+}+\mathbf{a}^{-} \cdot \mathbf{n}^{-}\right)\right) \cdot\left(b^{+} \mathbf{n}^{+}+b^{-} \mathbf{n}^{-}\right) d s \\
& \leq C\left(\sum_{K \in K^{+} \cup K^{-}} \frac{1}{C_{11}}\left\|\mathbf{a} \cdot \mathbf{n}_{K}\right\|_{0, \partial K}^{2}\right)^{1 / 2}\left(\int_{e} C_{11}|\llbracket b \rrbracket|^{2} d s\right)^{1 / 2} .
\end{aligned}
$$

Now we are ready to prove our main result.

Proof. [Proof of Theorem 3.1] Without loss of generality, we take $C_{11}(x)=c_{11}$ in the proof for the simplicity of the notation, where $c_{11}$ is a constant which might depend on the meshsize $h$. Let $\Pi \mathbf{q}$ be the $L^{2}$ projection of $\mathbf{q}$ onto $\mathbf{M}_{h}^{k}$, and $\mathcal{H} u \in V_{h}^{k}$ be the approximation function to $u$ described in Lemma 3.2. Notice

$$
\begin{aligned}
\left|\left(\mathbf{e}_{\mathbf{q}}, e_{u}\right)\right|_{\mathcal{A}} & =\left|\left(\mathbf{q}-\mathbf{\Pi q}+\mathbf{\Pi} \mathbf{q}-\mathbf{q}_{h}, u-\mathcal{H} u+\mathcal{H} u-u_{h}\right)\right|_{\mathcal{A}} \\
& \leq|(\mathbf{q}-\mathbf{\Pi q}, u-\mathcal{H} u)|_{\mathcal{A}}+\left|\left(\mathbf{\Pi} \mathbf{q}-\mathbf{q}_{h}, \mathcal{H} u-u_{h}\right)\right|_{\mathcal{A}} \\
& =\mathbf{I}+\mathbf{I I} .
\end{aligned}
$$


We now estimate the terms I and II separately.

$$
\begin{aligned}
\mathbf{I}^{2} & =|(\mathbf{q}-\Pi \mathbf{q}, u-\mathcal{H} u)|_{\mathcal{A}}^{2} \\
& =\mathcal{A}(\mathbf{q}-\Pi \mathbf{q}, u-\mathcal{H} u ; \mathbf{q}-\Pi \mathbf{q}, u-\mathcal{H} u) \\
& =a(\mathbf{q}-\Pi \mathbf{q}, \mathbf{q}-\Pi \mathbf{m})+c(u-\mathcal{H} u, u-\mathcal{H} u) \\
& \leq \sum_{K}\left(\|\mathbf{q}-\Pi \mathbf{q}\|_{0, K}^{2}+2 c_{11}\|u-\mathcal{H} u\|_{0, \partial K}^{2}\right) \\
& \leq C \sum_{K}\left(h_{K}^{2 \min \{s, k\}+2}\|\mathbf{q}\|_{s+1, K}^{2}+c_{11} h_{K}^{2 \min \{s+1, k\}+1}\|u\|_{s+2, K}^{2}\right) .
\end{aligned}
$$

In the last inequality we use the approximation results in Corollary 3.3.

$$
\begin{aligned}
\mathbf{I I}^{2}= & \mathcal{A}\left(\mathbf{\Pi q}-\mathbf{q}_{h}, \mathcal{H} u-u_{h} ; \mathbf{\Pi q}-\mathbf{q}_{h}, \mathcal{H} u-u_{h}\right) \\
= & \mathcal{A}\left(\mathbf{\Pi q}-\mathbf{q}, \mathcal{H} u-u ; \Pi \mathbf{q}-\mathbf{q}_{h}, \mathcal{H} u-u_{h}\right) \quad(\text { Galerkin orthogonality }) \\
= & a\left(\mathbf{\Pi q}-\mathbf{q}, \mathbf{\Pi q}-\mathbf{q}_{h}\right)+b\left(\mathcal{H} u-u, \mathbf{\Pi q}-\mathbf{q}_{h}\right) \\
& -b\left(\mathcal{H} u-u_{h}, \mathbf{\Pi q}-\mathbf{q}\right)+c\left(\mathcal{H} u-u, \mathcal{H} u-u_{h}\right) .
\end{aligned}
$$

Since $\boldsymbol{\Pi}$ is an $L^{2}$ projection from $\mathbf{M}$ to $\mathbf{M}_{h}$, from the definition of $a(\cdot, \cdot)$, the first term in (3.15) is zero. Now let us look at the second term in (3.15):

$$
\begin{aligned}
& b\left(\mathcal{H} u-u, \mathbf{\Pi} \mathbf{q}-\mathbf{q}_{h}\right)=-\sum_{K \in \mathcal{T}_{h}} \int_{K} \nabla(\mathcal{H} u-u) \cdot\left(\mathbf{\Pi} \mathbf{q}-\mathbf{q}_{h}\right) d x \\
& +\int_{\mathcal{E}_{i}}\left(\left\{\left\{\mathbf{\Pi} \mathbf{q}-\mathbf{q}_{h}\right\}\right\}-\mathbf{C}_{12} \llbracket \mathbf{\Pi} \mathbf{q}-\mathbf{q}_{h} \rrbracket\right) \cdot \llbracket \mathcal{H} u-u \rrbracket d s+\int_{\mathcal{E}_{D}}(\mathcal{H} u-u)\left(\mathbf{\Pi q}-\mathbf{q}_{h}\right) \cdot \mathbf{n} d s \\
\leq & \left(\sum_{K \in \mathcal{T}_{h}}\|\nabla(\mathcal{H} u-u)\|_{0, K}^{2}\right)^{1 / 2}\left(\sum_{K \in \mathcal{T}_{h}}\left\|\mathbf{\Pi} \mathbf{q}-\mathbf{q}_{h}\right\|_{0, K}^{2}\right)^{1 / 2} \\
& +C\left(\sum_{K \in \mathcal{T}_{h}} h_{K}\left\|\mathbf{\Pi} \mathbf{q}-\mathbf{q}_{h}\right\|_{0, \partial K}^{2}\right)^{1 / 2}\left(\sum_{K \in \mathcal{T}_{h}} \frac{1}{h_{K}}\|\mathcal{H} u-u\|_{0, \partial K}^{2}\right)^{1 / 2} \\
\leq & \left(\sum_{K \in \mathcal{T}_{h}}\|\nabla(\mathcal{H} u-u)\|_{0, K}^{2}+\frac{1}{h_{K}}\|\mathcal{H} u-u\|_{0, \partial K}^{2}\right)^{1 / 2}\left(\sum_{K \in \mathcal{T}_{h}}\left\|\mathbf{\Pi} \mathbf{q}-\mathbf{q}_{h}\right\|_{0, K}^{2}\right)^{1 / 2} .
\end{aligned}
$$

Here the inverse inequality (3.11) is used and $C$ depends on $\mathbf{C}_{12}$. Now we turn to estimate the third term in (3.15):

$$
\begin{aligned}
& b\left(\mathcal{H} u-u_{h}, \mathbf{\Pi} \mathbf{q}-\mathbf{q}\right)=-\sum_{K \in \mathcal{T}_{h}} \int_{K} \nabla\left(\mathcal{H} u-u_{h}\right) \cdot(\mathbf{\Pi q}-\mathbf{q}) d x \\
& +\int_{\mathcal{E}_{i}}\left(\{\{\mathbf{\Pi q}-\mathbf{q}\}\}-\mathbf{C}_{12} \llbracket \mathbf{\Pi} \mathbf{q}-\mathbf{q} \rrbracket\right) \cdot \llbracket \mathcal{H} u-u_{h} \rrbracket d s+\int_{\mathcal{E}_{D}}\left(\mathcal{H} u-u_{h}\right)(\mathbf{\Pi q}-\mathbf{q}) \cdot \mathbf{n} d s .
\end{aligned}
$$

The volume integral above is zero since $\boldsymbol{\Pi}$ is an $L^{2}$ projection from $\mathbf{M}$ to $\mathbf{M}_{h}$ and we 
have the inclusion relation (2.14): $\nabla V_{h} \subset \mathbf{M}_{h}$. Now we can apply Lemma 3.5 and get

$$
\begin{aligned}
& b\left(\mathcal{H} u-u_{h}, \mathbf{\Pi q}-\mathbf{q}\right) \\
\leq & C\left(\sum_{K \in \mathcal{T}_{h}} \frac{1}{c_{11}}\left\|(\mathbf{\Pi q}-\mathbf{q}) \cdot \mathbf{n}_{K}\right\|_{0, \partial K}^{2}\right)^{1 / 2} \\
& \times\left(\int_{\mathcal{E}_{i}} c_{11}\left|\llbracket \mathcal{H} u-u_{h} \rrbracket\right|^{2} d s+\int_{\mathcal{E}_{D}} c_{11}\left|\mathcal{H} u-u_{h}\right|^{2} d s\right)^{1 / 2} .
\end{aligned}
$$

The last term in (3.15) is

$$
\begin{aligned}
& c\left(\mathcal{H} u-u, \mathcal{H} u-u_{h}\right) \\
\leq & \left(\int_{\mathcal{E}_{i}} c_{11}|\llbracket \mathcal{H} u-u \rrbracket|^{2} d s+\int_{\mathcal{E}_{D}} c_{11}(\mathcal{H} u-u)^{2} d s\right)^{1 / 2} \\
& \times\left(\int_{\mathcal{E}_{i}} c_{11}\left|\llbracket \mathcal{H} u-u_{h} \rrbracket\right|^{2} d s+\int_{\mathcal{E}_{D}} c_{11}\left(\mathcal{H} u-u_{h}\right)^{2} d s\right)^{1 / 2} \\
\leq & C\left(\sum_{K \in \mathcal{T}_{h}} c_{11}\|\mathcal{H} u-u\|_{0, \partial K}^{2}\right)^{1 / 2}\left(\int_{\mathcal{E}_{i}} c_{11}\left|\llbracket \mathcal{H} u-u_{h} \rrbracket\right|^{2} d s+\int_{\mathcal{E}_{D}} c_{11}\left(\mathcal{H} u-u_{h}\right)^{2} d s\right)^{1 / 2} .
\end{aligned}
$$

Now by putting (3.16) (3.17) (3.18) together,

$$
\mathbf{I I}^{2} \leq C \mathbf{\Lambda}(\mathbf{\Pi} \mathbf{q}-\mathbf{q}, \mathcal{H} u-u) \mathbf{I I}
$$

where $C$ depends on $C_{12}$, and

$$
\boldsymbol{\Lambda}(\mathbf{p}, v)^{2}=\sum_{K \in \mathcal{T}_{h}}\left(\|\nabla v\|_{0, K}^{2}+\left(\frac{1}{h_{K}}+c_{11}\right)\|v\|_{0, \partial K}^{2}+\frac{1}{c_{11}}\left\|\mathbf{p} \cdot \mathbf{n}_{K}\right\|_{0, \partial K}^{2}\right) .
$$

Therefore we have

$$
\begin{aligned}
\mathbf{I I} & \leq C \boldsymbol{\Lambda}(\mathbf{\Pi q}-\mathbf{q}, \mathcal{H} u-u) \\
& \leq C\left\{\sum_{K \in \mathcal{T}_{h}}\left(\frac{1}{c_{11}} h_{K}^{2 \min \{s, k\}+1}\|\mathbf{q}\|_{s+1, K}^{2}+\left(c_{11}+\frac{1}{h_{K}}\right) h_{K}^{2 \min \{s+1, k\}+1}\|u\|_{s+2, K}^{2}\right)\right\}^{1 / 2}
\end{aligned}
$$

In the last step, we again use the approximation results in Lemma 3.2 and Corollary 3.3. Now combining (3.13) (3.14) (3.19), we obtain our main result in error estimate (3.2)-(3.4).

REMARK 3.6. We can get the same optimal error estimates as (3.2)-(3.4) if we replace the discrete spaces by $V_{h}^{k} \times \overline{\mathbf{M}}_{h}^{k}$. If we instead use $V_{h}^{k} \times \overline{\mathbf{M}}_{h}^{k-1}$, the inclusion relation (2.14) still holds and we can get the estimate as (3.2) yet with

$$
P= \begin{cases}\min \left\{s+\frac{1}{2}, k-\frac{1}{2}\right\} & C_{11} \sim O(1) \\ \min \{s+1, k\} & C_{11} \sim O\left(h^{-1}\right)\end{cases}
$$

In other word, $C_{11} \sim O(1)$ does not give optimal error estimate results in this case. 
REMARK 3.7. Unfortunately, a direct application of the standard duality argument [2] can not provide the error estimate for $u$ in the $L^{2}$-norm due to the choice of the solution space. This issue will be addressed elsewhere. Numerically, however, we observe the optimal convergence rate for $u$ in the $L^{2}$-norm, see Tables 4.1-4.2 in Section 4 .

4. Numerical results. In this section, we include two numerical examples in the two dimensional case. One is the smooth example with the exact solution $u(x, y)=$ $e^{-x} \cos (y)$ on $[0,1] \times[0,1]$. The other is the singular example with the exact solution $u(x, y)=r^{\alpha} \sin (\alpha \theta)$ on $[0,1] \times[0,1]$, where $(r, \theta)$ is the polar coordinate and $\alpha=4 / 3$. The Dirichlet boundary condition with empty Neumann boundary is considered in both cases. We also compute the singular example with $\alpha=2 / 3$ and obtain similar results, which are not included here to save space. The computation is performed on uniform rectangular meshes, with the parameter $C_{12}$ to be along the (pre-chosen) direction of the normal vector of each edge with the modulus $1 / 2$ (see Remark 2.1). Diagonally pre-conditioned Conjugate Gradient iterative method is used to solve the final linear system, the stopping criterion is such that the relative residual error is less than $10^{-13}$.

The following notations are used in Tables 4.1-4.8: LSP means the local-structurepreserving LDG method; Std means the standard LDG method; Mix means the localstructure-preserving LDG method with $V_{h}^{k} \times \overline{\mathbf{M}}_{h}^{k}$ as the solution spaces.

4.1. Validation of the error estimate with different $C_{11}$. We first check the convergence behavior of our local-structure-preserving LDG method for smooth and singular solutions with different stabilizing parameter $C_{11}$, see Tables 4.1 and 4.2. For both $C_{11}=10=O(1)$ and $C_{11}=1 / h=O(1 / h)$, the theoretical convergence result is confirmed. The errors for both cases are in the same magnitude. Moreover, the case with $C_{11}=O(1)$ seems to give relatively better convergence rates for $\mathbf{q}_{h}$ in the $L^{2}$-norm and for $\left(u_{h}, \mathbf{q}_{h}\right)$ in the energy norm, and the convergence rates are also higher than the theoretically expected ones. Although we have not provided an error estimate for $u$ in the $L^{2}$-norm theoretically, we observe numerically the $(k+1)$-th order convergence rate for smooth solutions which are optimal.

4.2. Comparison of the local-structure-preserving LDG method and the standard LDG method. When we introduce the local-structure-preserving LDG method, we claim that by doing so, the size of the final linear system is greatly reduced due to the choice of the solution spaces. In this subsection, we show that this theoretically less expensive method will produce comparable results as the standard LDG methods do for both the smooth example and the singular example with different choices of the stabilizing parameter $C_{11}$, see Tables 4.3-4.6. Therefore we conclude that we provide a less expensive method which can produce equally good approximations.

4.3. The local-structure-preserving LDG method with $\mathbf{M}_{h}$ or $\overline{\mathbf{M}}_{h}$ as the space for $\mathbf{q}_{h}$. In this subsection, we use $V_{h}^{k} \times \mathbf{M}_{h}^{k}$ and $V_{h}^{k} \times \overline{\mathbf{M}}_{h}^{k}$ as the solution spaces in the local-structure-preserving LDG method (2.17). Similar convergence rates and comparable numerical results are observed, see Tables 4.7-4.8. Notice that in actual implementation, once the inclusion relation (2.14) and the approximation properties in Lemma 3.2 and Corollary 3.3 are satisfied, there is still plenty of room for choosing the space for the auxiliary variable $\mathbf{q}_{h}$. The $P^{1}$ results are not included in the tables as they are actually the same as the $P^{1}$ results in Tables 4.3 and 4.4. 
TABLE 4.1

Local-structure-preserving LDG solutions with different parameter $C_{11}$ for the smooth example $u(x, y)=e^{-x} \cos (y) . h_{0}=0.1$.

\begin{tabular}{|c|c|c|c|c|c|c|}
\hline meshsize $h$ & $\left\|e_{u}\right\|_{0}$ & rate & $\left\|\mathbf{e}_{\mathbf{q}}\right\|_{0}$ & rate & $\left(\mathbf{e}_{\mathbf{q}}, \mathbf{e}_{\mathbf{u}}\right) \|_{\mathcal{A}}$ & rate \\
\hline \multicolumn{7}{|c|}{$P^{1}$-LSP with $C_{11}=10$} \\
\hline$h_{0}$ & $5.33 \mathrm{E}-04$ & & $6.61 \mathrm{E}-03$ & - & $3.15 \mathrm{E}-02$ & - \\
\hline$h_{0} / 2$ & $1.41 \mathrm{E}-04$ & 1.92 & 2.07E-03 & 1.67 & $6.64 \mathrm{E}-03$ & 1.44 \\
\hline$h_{0} / 4$ & $3.64 \mathrm{E}-05$ & 1.95 & $6.28 \mathrm{E}-04$ & 1.72 & $2.40 \mathrm{E}-03$ & 1.47 \\
\hline$h_{0} / 8$ & $9.30 \mathrm{E}-06$ & 1.97 & $1.89 \mathrm{E}-04$ & 1.74 & 8.57E-04 & 1.48 \\
\hline$h_{0} / 16$ & $2.35 \mathrm{E}-06$ & 1.98 & $5.63 \mathrm{E}-05$ & 1.74 & $3.04 \mathrm{E}-04$ & 1.49 \\
\hline$h_{0} / 32$ & $5.91 \mathrm{E}-07$ & 1.99 & $1.67 \mathrm{E}-05$ & 1.75 & $1.08 \mathrm{E}-04$ & 1.50 \\
\hline \multicolumn{7}{|c|}{$P^{1}$-LSP with $C_{11}=1 / h$} \\
\hline$h_{0}$ & $5.33 \mathrm{E}-04$ & - & $6.61 \mathrm{E}-03$ & - & $1.80 \mathrm{E}-02$ & - \\
\hline$h_{0} / 2$ & $1.34 \mathrm{E}-04$ & 1.99 & $3.11 \mathrm{E}-03$ & 1.08 & $9.04 \mathrm{E}-03$ & 1.00 \\
\hline$h_{0} / 4$ & $3.36 \mathrm{E}-05$ & 1.99 & $1.50 \mathrm{E}-03$ & 1.05 & $4.52 \mathrm{E}-03$ & 1.00 \\
\hline$h_{0} / 8$ & $8.42 \mathrm{E}-06$ & 2.00 & 7.34E-04 & 1.03 & $2.26 \mathrm{E}-03$ & 1.00 \\
\hline$h_{0} / 16$ & $2.11 \mathrm{E}-06$ & 2.00 & 3.63E-04 & 1.02 & $1.13 \mathrm{E}-03$ & 1.00 \\
\hline$h_{0} / 32$ & $5.27 \mathrm{E}-07$ & 2.00 & $1.80 \mathrm{E}-04$ & 1.01 & $5.66 \mathrm{E}-04$ & 1.00 \\
\hline \multicolumn{7}{|c|}{$P^{2}$-LSP with $C_{11}=10$} \\
\hline$h_{0}$ & $1.20 \mathrm{E}-05$ & - & $2.89 \mathrm{E}-04$ & - & $4.71 \mathrm{E}-04$ & - \\
\hline$h_{0} / 2$ & 1.93E-06 & 2.64 & $5.16 \mathrm{E}-05$ & 2.49 & $9.55 \mathrm{E}-05$ & 2.30 \\
\hline$h_{0} / 4$ & $2.92 \mathrm{E}-07$ & 2.73 & $8.08 \mathrm{E}-06$ & 2.67 & $1.85 \mathrm{E}-05$ & 2.37 \\
\hline$h_{0} / 8$ & $4.11 \mathrm{E}-08$ & 2.83 & $1.15 \mathrm{E}-06$ & 2.81 & $3.46 \mathrm{E}-06$ & 2.42 \\
\hline$h_{0} / 16$ & $5.48 \mathrm{E}-09$ & 2.90 & $1.56 \mathrm{E}-07$ & 2.89 & $6.31 \mathrm{E}-07$ & 2.46 \\
\hline$h_{0} / 32$ & $7.10 \mathrm{E}-10$ & 2.95 & $2.04 \mathrm{E}-08$ & 2.93 & $1.13 \mathrm{E}-07$ & 2.48 \\
\hline \multicolumn{7}{|c|}{$P^{2}$-LSP with $C_{11}=1 / h$} \\
\hline$h_{0}$ & $1.20 \mathrm{E}-05$ & - & $2.89 \mathrm{E}-04$ & - & $4.71 \mathrm{E}-04$ & - \\
\hline$h_{0} / 2$ & $1.53 \mathrm{E}-06$ & 2.97 & $7.51 \mathrm{E}-05$ & 1.95 & $1.20 \mathrm{E}-04$ & 1.97 \\
\hline$h_{0} / 4$ & $1.93 \mathrm{E}-07$ & 2.99 & $1.91 \mathrm{E}-05$ & 1.97 & $3.04 \mathrm{E}-05$ & 1.98 \\
\hline$h_{0} / 8$ & $2.43 \mathrm{E}-08$ & 2.99 & $4.82 \mathrm{E}-06$ & 1.99 & 7.65E-06 & 1.99 \\
\hline$h_{0} / 16$ & $3.04 \mathrm{E}-09$ & 2.99 & $1.21 \mathrm{E}-06$ & 1.99 & $1.92 \mathrm{E}-06$ & 2.00 \\
\hline$h_{0} / 32$ & $3.81 \mathrm{E}-10$ & 3.00 & 3.03E-07 & 2.00 & $4.80 \mathrm{E}-07$ & 2.00 \\
\hline \multicolumn{7}{|c|}{$P^{P^{3} \text {-LSP with } C_{11}=10}$} \\
\hline$h_{0}$ & $2.31 \mathrm{E}-07$ & - & $5.65 \mathrm{E}-06$ & - & $7.78 \mathrm{E}-06$ & - \\
\hline$h_{0} / 2$ & $1.74 \mathrm{E}-08$ & 3.73 & $5.33 \mathrm{E}-07$ & 3.41 & $8.10 \mathrm{E}-07$ & 3.26 \\
\hline$h_{0} / 4$ & $1.26 \mathrm{E}-09$ & 3.79 & $4.78 \mathrm{E}-08$ & 3.48 & $8.11 \mathrm{E}-08$ & 3.32 \\
\hline$h_{0} / 8$ & $8.71 \mathrm{E}-11$ & 3.85 & 4.44E-09 & 3.43 & 7.97E-09 & 3.35 \\
\hline$h_{0} / 16$ & $5.57 \mathrm{E}-12$ & 3.97 & $4.50 \mathrm{E}-10$ & 3.30 & $7.85 \mathrm{E}-10$ & 3.34 \\
\hline \multicolumn{7}{|c|}{ 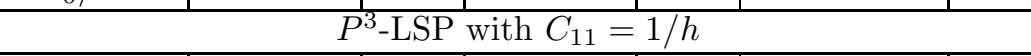 } \\
\hline$h_{0}$ & $2.31 \mathrm{E}-07$ & - & $5.65 \mathrm{E}-06$ & - & $7.78 \mathrm{E}-06$ & - \\
\hline$h_{0} / 2$ & $1.46 \mathrm{E}-08$ & 3.98 & $7.21 \mathrm{E}-07$ & 2.97 & $9.85 \mathrm{E}-07$ & 2.98 \\
\hline$h_{0} / 4$ & $9.15 \mathrm{E}-10$ & 3.99 & $9.10 \mathrm{E}-08$ & 2.99 & $1.24 \mathrm{E}-07$ & 2.99 \\
\hline$h_{0} / 8$ & $5.74 \mathrm{E}-11$ & 3.99 & $1.14 \mathrm{E}-08$ & 2.99 & $1.55 \mathrm{E}-08$ & 3.00 \\
\hline$h_{0} / 16$ & $4.11 \mathrm{E}-12$ & 3.80 & 1.43E-09 & 3.00 & 1.94E-09 & 3.00 \\
\hline
\end{tabular}


TABLE 4.2

Local-structure-preserving $L D G$ solutions with different parameter $C_{11}$ for the singular example $u(x, y)=r^{\alpha} \sin (\alpha \theta)$, where $(r, \theta)$ is the polar coordinate and $\alpha=4 / 3 . h_{0}=0.1$.

\begin{tabular}{|c|c|c|c|c|c|c|}
\hline meshsize $h$ & $\left\|e_{u}\right\|_{0}$ & rate & $\left\|\mathbf{e}_{\mathbf{q}}\right\|_{0}$ & rate & $\left(\mathbf{e}_{\mathbf{q}}, \mathbf{e}_{\mathbf{u}}\right) \|_{\mathcal{A}}$ & rate \\
\hline \multicolumn{7}{|c|}{$P^{1}$-LSP with $C_{11}=10$} \\
\hline$h_{0}$ & $5.72 \mathrm{E}-04$ & & $8.36 \mathrm{E}-03$ & - & $2.46 \mathrm{E}-02$ & - \\
\hline$h_{0} / 2$ & $1.47 \mathrm{E}-04$ & 1.96 & $3.21 \mathrm{E}-03$ & 1.38 & $9.13 \mathrm{E}-03$ & 1.43 \\
\hline$h_{0} / 4$ & $3.78 \mathrm{E}-05$ & 1.97 & $1.24 \mathrm{E}-03$ & 1.37 & $3.35 \mathrm{E}-03$ & 1.45 \\
\hline$h_{0} / 8$ & $9.62 \mathrm{E}-06$ & 1.97 & $4.81 \mathrm{E}-04$ & 1.36 & $1.22 \mathrm{E}-03$ & 1.46 \\
\hline$h_{0} / 16$ & $2.45 \mathrm{E}-06$ & 1.98 & $1.88 \mathrm{E}-04$ & 1.35 & $4.43 \mathrm{E}-04$ & 1.46 \\
\hline$h_{0} / 32$ & $6.23 \mathrm{E}-07$ & 1.97 & $7.44 \mathrm{E}-05$ & 1.34 & $1.62 \mathrm{E}-04$ & 1.46 \\
\hline \multicolumn{7}{|c|}{$P^{1}$-LSP with $C_{11}=1 / h$} \\
\hline$h_{0}$ & $5.72 \mathrm{E}-04$ & - & $8.36 \mathrm{E}-03$ & - & $2.46 \mathrm{E}-02$ & - \\
\hline$h_{0} / 2$ & $1.46 \mathrm{E}-04$ & 1.97 & $3.54 \mathrm{E}-03$ & 1.24 & $1.25 \mathrm{E}-02$ & 0.98 \\
\hline$h_{0} / 4$ & $3.70 \mathrm{E}-05$ & 1.98 & $1.53 \mathrm{E}-03$ & 1.21 & $6.29 \mathrm{E}-03$ & 0.99 \\
\hline$h_{0} / 8$ & $9.35 \mathrm{E}-06$ & 1.98 & $6.77 \mathrm{E}-04$ & 1.18 & $3.16 \mathrm{E}-03$ & 0.99 \\
\hline$h_{0} / 16$ & $2.36 \mathrm{E}-06$ & 1.99 & $3.08 \mathrm{E}-04$ & 1.14 & $1.59 \mathrm{E}-03$ & 0.99 \\
\hline$h_{0} / 32$ & $5.92 \mathrm{E}-07$ & 1.99 & $1.43 \mathrm{E}-04$ & 1.10 & $7.96 \mathrm{E}-04$ & 1.00 \\
\hline \multicolumn{7}{|c|}{$P^{2}$-LSP with $C_{11}=10$} \\
\hline$h_{0}$ & $5.30 \mathrm{E}-05$ & - & $2.35 \mathrm{E}-03$ & - & $2.83 \mathrm{E}-03$ & - \\
\hline$h_{0} / 2$ & $1.13 \mathrm{E}-05$ & 2.23 & $9.03 \mathrm{E}-04$ & 1.38 & $1.02 \mathrm{E}-03$ & 1.48 \\
\hline$h_{0} / 4$ & $2.36 \mathrm{E}-06$ & 2.26 & $3.52 \mathrm{E}-04$ & 1.36 & $3.78 \mathrm{E}-04$ & 1.43 \\
\hline$h_{0} / 8$ & $4.84 \mathrm{E}-07$ & 2.28 & $1.38 \mathrm{E}-04$ & 1.35 & $1.44 \mathrm{E}-04$ & 1.39 \\
\hline$h_{0} / 16$ & $9.81 \mathrm{E}-08$ & 2.30 & $5.47 \mathrm{E}-05$ & 1.34 & $5.58 \mathrm{E}-05$ & 1.37 \\
\hline$h_{0} / 32$ & $1.97 \mathrm{E}-08$ & 2.32 & $2.16 \mathrm{E}-05$ & 1.34 & $2.19 \mathrm{E}-05$ & 1.35 \\
\hline \multicolumn{7}{|c|}{$P^{2}$-LSP with $C_{11}=1 / h$} \\
\hline$h_{0}$ & $5.30 \mathrm{E}-05$ & - & $2.35 \mathrm{E}-03$ & - & $2.83 \mathrm{E}-03$ & - \\
\hline$h_{0} / 2$ & $1.06 \mathrm{E}-05$ & 2.33 & $9.32 \mathrm{E}-04$ & 1.33 & $1.12 \mathrm{E}-03$ & 1.33 \\
\hline$h_{0} / 4$ & $2.10 \mathrm{E}-06$ & 2.33 & $3.70 \mathrm{E}-04$ & 1.33 & $4.46 \mathrm{E}-04$ & 1.33 \\
\hline$h_{0} / 8$ & $4.17 \mathrm{E}-07$ & 2.33 & $1.47 \mathrm{E}-04$ & 1.33 & $1.77 \mathrm{E}-04$ & 1.33 \\
\hline$h_{0} / 16$ & $8.27 \mathrm{E}-08$ & 2.33 & $5.83 \mathrm{E}-05$ & 1.33 & 7.03E-05 & 1.33 \\
\hline$h_{0} / 32$ & $1.64 \mathrm{E}-08$ & 2.33 & $2.31 \mathrm{E}-05$ & 1.33 & $2.79 \mathrm{E}-05$ & 1.33 \\
\hline \multicolumn{7}{|c|}{$\begin{array}{l}P^{3} \text {-LSP with } C_{11}=10 \\
\end{array}$} \\
\hline$h_{0}$ & $1.98 \mathrm{E}-05$ & - & $1.62 \mathrm{E}-03$ & - & $1.73 \mathrm{E}-03$ & - \\
\hline$h_{0} / 2$ & $4.23 \mathrm{E}-06$ & 2.23 & $6.34 \mathrm{E}-04$ & 1.36 & $6.58 \mathrm{E}-04$ & 1.39 \\
\hline$h_{0} / 4$ & $9.01 \mathrm{E}-07$ & 2.23 & $2.48 \mathrm{E}-04$ & 1.35 & $2.54 \mathrm{E}-04$ & 1.37 \\
\hline$h_{0} / 8$ & $1.89 \mathrm{E}-07$ & 2.25 & $9.78 \mathrm{E}-05$ & 1.35 & $9.90 \mathrm{E}-05$ & 1.36 \\
\hline$h_{0} / 16$ & $3.91 \mathrm{E}-08$ & 2.27 & $3.86 \mathrm{E}-05$ & 1.34 & $3.89 \mathrm{E}-05$ & 1.35 \\
\hline \multicolumn{7}{|c|}{ 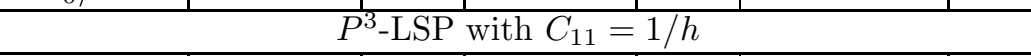 } \\
\hline$h_{0}$ & $1.98 \mathrm{E}-05$ & - & $1.62 \mathrm{E}-03$ & - & $1.73 \mathrm{E}-03$ & - \\
\hline$h_{0} / 2$ & 3.93E-06 & 2.33 & $6.44 \mathrm{E}-04$ & 1.33 & $6.87 \mathrm{E}-04$ & 1.33 \\
\hline$h_{0} / 4$ & $7.80 \mathrm{E}-07$ & 2.33 & $2.56 \mathrm{E}-04$ & 1.33 & $2.72 \mathrm{E}-04$ & 1.33 \\
\hline$h_{0} / 8$ & $1.54 \mathrm{E}-07$ & 2.33 & $1.01 \mathrm{E}-04$ & 1.33 & $1.08 \mathrm{E}-04$ & 1.33 \\
\hline$h_{0} / 16$ & $3.07 \mathrm{E}-08$ & 2.33 & $4.03 \mathrm{E}-05$ & 1.33 & $4.29 \mathrm{E}-05$ & 1.33 \\
\hline
\end{tabular}


TABLE 4.3

Local-structure-preserving $L D G$ solutions and the standard $L D G$ solutions for the smooth example $u(x, y)=e^{-x} \cos (y) . C_{11}=10 . h_{0}=0.1$.

\begin{tabular}{|c|c|c|c|c|c|c|}
\hline meshsize $h$ & $\left\|e_{u}\right\|_{0}$ & rate & $\left\|\mathbf{e}_{\mathbf{q}}\right\|_{0}$ & rate & $\left(\mathbf{e}_{\mathbf{q}}, \mathbf{e}_{\mathbf{u}}\right) \|_{\mathcal{A}}$ & rate \\
\hline \multicolumn{7}{|c|}{$P^{1}-\mathrm{LSP}$} \\
\hline$h_{0}$ & $5.33 \mathrm{E}-04$ & - & $6.61 \mathrm{E}-03$ & - & $3.15 \mathrm{E}-02$ & - \\
\hline$h_{0} / 2$ & $1.41 \mathrm{E}-04$ & 1.92 & 2.07E-03 & 1.67 & $6.64 \mathrm{E}-03$ & 1.44 \\
\hline$h_{0} / 4$ & $3.64 \mathrm{E}-05$ & 1.95 & $6.28 \mathrm{E}-04$ & 1.72 & $2.40 \mathrm{E}-03$ & 1.47 \\
\hline$h_{0} / 8$ & $9.30 \mathrm{E}-06$ & 1.97 & 1.89E-04 & 1.74 & 8.57E-04 & 1.48 \\
\hline$h_{0} / 16$ & $2.35 \mathrm{E}-06$ & 1.98 & $5.63 \mathrm{E}-05$ & 1.74 & $3.04 \mathrm{E}-04$ & 1.49 \\
\hline$h_{0} / 32$ & 5.91E-07 & 1.99 & $1.67 \mathrm{E}-05$ & 1.75 & 1.08E-04 & 1.50 \\
\hline \multicolumn{7}{|c|}{$P^{1}-$ Std } \\
\hline$h_{0}$ & $5.33 \mathrm{E}-04$ & - & $6.78 \mathrm{E}-03$ & - & $1.81 \mathrm{E}-02$ & - \\
\hline$h_{0} / 2$ & 1.40E-04 & 1.93 & $2.16 \mathrm{E}-03$ & 1.65 & $6.66 \mathrm{E}-03$ & 1.44 \\
\hline$h_{0} / 4$ & $3.62 \mathrm{E}-05$ & 1.95 & 6.79E-04 & 1.67 & $2.41 \mathrm{E}-03$ & 1.47 \\
\hline$h_{0} / 8$ & $9.21 \mathrm{E}-06$ & 1.97 & 2.18E-04 & 1.64 & 8.62E-04 & 1.48 \\
\hline$h_{0} / 16$ & $2.32 \mathrm{E}-06$ & 1.99 & $7.26 \mathrm{E}-05$ & 1.59 & $3.06 \mathrm{E}-04$ & 1.49 \\
\hline$h_{0} / 32$ & $5.84 \mathrm{E}-07$ & 1.99 & $2.48 \mathrm{E}-05$ & 1.55 & 1.09E-04 & 1.50 \\
\hline \multicolumn{7}{|c|}{$P^{2}$-LSP } \\
\hline$h_{0}$ & $1.20 \mathrm{E}-05$ & - & $2.89 \mathrm{E}-04$ & - & $4.71 \mathrm{E}-04$ & - \\
\hline$h_{0} / 2$ & $1.93 \mathrm{E}-06$ & 2.64 & $5.16 \mathrm{E}-05$ & 2.49 & $9.55 \mathrm{E}-05$ & 2.30 \\
\hline$h_{0} / 4$ & $2.92 \mathrm{E}-07$ & 2.73 & 8.08E-06 & 2.67 & $1.85 \mathrm{E}-05$ & 2.37 \\
\hline$h_{0} / 8$ & 4.11E-08 & 2.83 & $1.15 \mathrm{E}-06$ & 2.81 & $3.46 \mathrm{E}-06$ & 2.42 \\
\hline$h_{0} / 16$ & $5.48 \mathrm{E}-09$ & 2.90 & $1.56 \mathrm{E}-07$ & 2.89 & $6.31 \mathrm{E}-07$ & 2.46 \\
\hline$h_{0} / 32$ & $7.10 \mathrm{E}-10$ & 2.95 & $2.04 \mathrm{E}-08$ & 2.93 & $1.13 \mathrm{E}-07$ & 2.48 \\
\hline \multicolumn{7}{|c|}{$P^{2}-$ Std } \\
\hline$h_{0}$ & $8.55 \mathrm{E}-06$ & - & $4.70 \mathrm{E}-04$ & - & $5.52 \mathrm{E}-04$ & - \\
\hline$h_{0} / 2$ & $1.08 \mathrm{E}-06$ & 2.98 & $1.21 \mathrm{E}-04$ & 1.95 & 1.32E-04 & 2.06 \\
\hline$h_{0} / 4$ & $1.36 \mathrm{E}-07$ & 2.99 & $3.11 \mathrm{E}-05$ & 1.97 & $3.24 \mathrm{E}-05$ & 2.03 \\
\hline$h_{0} / 8$ & $1.70 \mathrm{E}-08$ & 3.00 & 7.86E-06 & 1.98 & 8.03E-06 & 2.01 \\
\hline$h_{0} / 16$ & 2.13E-09 & 3.00 & $1.98 \mathrm{E}-06$ & 2.00 & $2.00 \mathrm{E}-06$ & 2.00 \\
\hline$h_{0} / 32$ & $2.67 \mathrm{E}-10$ & 3.00 & $4.96 \mathrm{E}-07$ & 2.00 & $4.98 \mathrm{E}-07$ & 2.00 \\
\hline \multicolumn{7}{|c|}{$P^{3}-\mathrm{LSP}$} \\
\hline$h_{0}$ & $2.31 \mathrm{E}-07$ & - & $5.65 \mathrm{E}-06$ & - & $7.78 \mathrm{E}-06$ & - \\
\hline$h_{0} / 2$ & $1.74 \mathrm{E}-08$ & 3.73 & 5.33E-07 & 3.41 & $8.10 \mathrm{E}-07$ & 3.26 \\
\hline$h_{0} / 4$ & $1.26 \mathrm{E}-09$ & 3.79 & $4.78 \mathrm{E}-08$ & 3.48 & $8.11 \mathrm{E}-08$ & 3.32 \\
\hline$h_{0} / 8$ & 8.71E-11 & 3.85 & 4.44E-09 & 3.43 & 7.97E-09 & 3.35 \\
\hline$h_{0} / 16$ & $5.57 \mathrm{E}-12$ & 3.97 & $4.50 \mathrm{E}-10$ & 3.30 & 7.85E-10 & 3.34 \\
\hline \multicolumn{7}{|c|}{$P^{3}-$ Std } \\
\hline$h_{0}$ & $1.32 \mathrm{E}-07$ & - & $6.52 \mathrm{E}-06$ & - & $7.57 \mathrm{E}-06$ & - \\
\hline$h_{0} / 2$ & 8.61E-09 & 3.94 & $8.24 \mathrm{E}-07$ & 2.98 & 8.96E-07 & 3.08 \\
\hline$h_{0} / 4$ & $5.51 \mathrm{E}-10$ & 3.97 & 1.03E-07 & 2.99 & $1.08 \mathrm{E}-07$ & 3.05 \\
\hline$h_{0} / 8$ & $3.50 \mathrm{E}-11$ & 3.98 & $1.30 \mathrm{E}-08$ & 3.00 & $1.33 \mathrm{E}-08$ & 3.03 \\
\hline$h_{0} / 16$ & $3.17 \mathrm{E}-12$ & 3.46 & 1.63E-09 & 3.00 & $1.65 \mathrm{E}-09$ & 3.01 \\
\hline
\end{tabular}


TABLE 4.4

Local-structure-preserving $L D G$ solutions and the standard $L D G$ solutions for the smooth example $u(x, y)=e^{-x} \cos (y) . C_{11}=1 / h . h_{0}=0.1$.

\begin{tabular}{|c|c|c|c|c|c|c|}
\hline meshsize $h$ & $\left\|e_{u}\right\|_{0}$ & rate & $\left\|\mathbf{e}_{\mathbf{q}}\right\|_{0}$ & rate & $\left(\mathbf{e}_{\mathbf{q}}, \mathbf{e}_{\mathbf{u}}\right) \|_{\mathcal{A}}$ & rate \\
\hline \multicolumn{7}{|c|}{$P^{1}-\mathrm{LSP}$} \\
\hline$h_{0}$ & $5.33 \mathrm{E}-04$ & 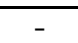 & $6.61 \mathrm{E}-03$ & - & $1.80 \mathrm{E}-02$ & - \\
\hline$h_{0} / 2$ & $1.34 \mathrm{E}-04$ & 1.99 & $3.11 \mathrm{E}-03$ & 1.08 & $9.04 \mathrm{E}-03$ & 1.00 \\
\hline$h_{0} / 4$ & $3.36 \mathrm{E}-05$ & 1.99 & $1.50 \mathrm{E}-03$ & 1.05 & $4.52 \mathrm{E}-03$ & 1.00 \\
\hline$h_{0} / 8$ & $8.42 \mathrm{E}-06$ & 2.00 & 7.34E-04 & 1.03 & $2.26 \mathrm{E}-03$ & 1.00 \\
\hline$h_{0} / 16$ & $2.11 \mathrm{E}-06$ & 2.00 & $3.63 \mathrm{E}-04$ & 1.02 & $1.13 \mathrm{E}-03$ & 1.00 \\
\hline$h_{0} / 32$ & $5.27 \mathrm{E}-07$ & 2.00 & $1.80 \mathrm{E}-04$ & 1.01 & $5.66 \mathrm{E}-04$ & 1.00 \\
\hline \multicolumn{7}{|c|}{$P^{1}-$ Std } \\
\hline$h_{0}$ & $5.33 \mathrm{E}-04$ & 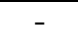 & $6.78 \mathrm{E}-03$ & - & $1.81 \mathrm{E}-02$ & - \\
\hline$h_{0} / 2$ & $1.34 \mathrm{E}-04$ & 1.99 & $3.16 \mathrm{E}-03$ & 1.10 & $9.05 \mathrm{E}-03$ & 1.00 \\
\hline$h_{0} / 4$ & $3.36 \mathrm{E}-05$ & 2.00 & $1.51 \mathrm{E}-03$ & 1.06 & $4.52 \mathrm{E}-03$ & 1.00 \\
\hline$h_{0} / 8$ & $8.43 \mathrm{E}-06$ & 2.00 & 7.37E-04 & 1.04 & $2.26 \mathrm{E}-03$ & 1.00 \\
\hline$h_{0} / 16$ & $2.11 \mathrm{E}-06$ & 2.00 & $3.64 \mathrm{E}-04$ & 1.02 & $1.13 \mathrm{E}-03$ & 1.00 \\
\hline$h_{0} / 32$ & $5.27 \mathrm{E}-07$ & 2.00 & $1.81 \mathrm{E}-04$ & 1.02 & $5.66 \mathrm{E}-04$ & 1.00 \\
\hline \multicolumn{7}{|c|}{$4 P^{2}$-LSP } \\
\hline$h_{0}$ & $1.20 \mathrm{E}-05$ & - & $2.89 \mathrm{E}-04$ & - & $4.71 \mathrm{E}-04$ & - \\
\hline$h_{0} / 2$ & $1.53 \mathrm{E}-06$ & 2.97 & 7.51E-05 & 1.95 & $1.20 \mathrm{E}-04$ & 1.97 \\
\hline$h_{0} / 4$ & 1.93E-07 & 2.99 & $1.91 \mathrm{E}-05$ & 1.97 & $3.04 \mathrm{E}-05$ & 1.98 \\
\hline$h_{0} / 8$ & $2.43 \mathrm{E}-08$ & 2.99 & $4.82 \mathrm{E}-06$ & 1.99 & $7.65 \mathrm{E}-06$ & 1.99 \\
\hline$h_{0} / 16$ & $3.04 \mathrm{E}-09$ & 2.99 & $1.21 \mathrm{E}-06$ & 1.99 & $1.92 \mathrm{E}-06$ & 2.00 \\
\hline$h_{0} / 32$ & $3.81 \mathrm{E}-10$ & 3.00 & 3.03E-07 & 2.00 & $4.80 \mathrm{E}-07$ & 2.00 \\
\hline \multicolumn{7}{|c|}{$P^{2}$-Std } \\
\hline$h_{0}$ & $8.55 \mathrm{E}-06$ & - & $4.70 \mathrm{E}-04$ & - & $5.52 \mathrm{E}-04$ & - \\
\hline$h_{0} / 2$ & $1.06 \mathrm{E}-06$ & 3.02 & $1.23 \mathrm{E}-04$ & 1.93 & $1.42 \mathrm{E}-04$ & 1.96 \\
\hline$h_{0} / 4$ & $1.31 \mathrm{E}-07$ & 3.01 & $3.14 \mathrm{E}-05$ & 1.97 & $3.60 \mathrm{E}-05$ & 1.98 \\
\hline$h_{0} / 8$ & $1.64 \mathrm{E}-08$ & 3.00 & $7.95 \mathrm{E}-06$ & 1.98 & $9.06 \mathrm{E}-06$ & 1.99 \\
\hline$h_{0} / 16$ & $2.04 \mathrm{E}-09$ & 3.00 & $2.00 \mathrm{E}-06$ & 1.99 & $2.27 \mathrm{E}-06$ & 2.00 \\
\hline$h_{0} / 32$ & $2.56 \mathrm{E}-10$ & 3.00 & $5.01 \mathrm{E}-07$ & 2.00 & $5.69 \mathrm{E}-07$ & 2.00 \\
\hline \multicolumn{7}{|c|}{$\overline{P P^{3} \text {-LSP }}$} \\
\hline$h_{0}$ & $2.31 \mathrm{E}-07$ & - & $5.65 \mathrm{E}-06$ & - & $7.78 \mathrm{E}-06$ & - \\
\hline$h_{0} / 2$ & $1.46 \mathrm{E}-08$ & 3.98 & $7.21 \mathrm{E}-07$ & 2.97 & $9.85 \mathrm{E}-07$ & 2.98 \\
\hline$h_{0} / 4$ & $9.15 \mathrm{E}-10$ & 3.99 & $9.10 \mathrm{E}-08$ & 2.99 & $1.24 \mathrm{E}-07$ & 2.99 \\
\hline$h_{0} / 8$ & $5.74 \mathrm{E}-11$ & 3.99 & $1.14 \mathrm{E}-08$ & 2.99 & $1.55 \mathrm{E}-08$ & 3.00 \\
\hline$h_{0} / 16$ & $4.11 \mathrm{E}-12$ & 3.80 & $1.43 \mathrm{E}-09$ & 3.00 & $1.94 \mathrm{E}-09$ & 3.00 \\
\hline \multicolumn{7}{|c|}{$P^{3}-$ Std } \\
\hline$h_{0}$ & $1.31 \mathrm{E}-07$ & - & $6.52 \mathrm{E}-06$ & - & $7.57 \mathrm{E}-06$ & - \\
\hline$h_{0} / 2$ & 8.30E-09 & 3.99 & 8.39E-07 & 2.96 & $9.64 \mathrm{E}-07$ & 2.97 \\
\hline$h_{0} / 4$ & $5.21 \mathrm{E}-10$ & 4.00 & $1.06 \mathrm{E}-07$ & 2.98 & $1.22 \mathrm{E}-07$ & 2.99 \\
\hline$h_{0} / 8$ & $3.28 \mathrm{E}-11$ & 3.99 & $1.34 \mathrm{E}-08$ & 2.99 & $1.53 \mathrm{E}-08$ & 2.99 \\
\hline$h_{0} / 16$ & $8.45 \mathrm{E}-12$ & 1.96 & 1.68E-09 & 2.99 & 1.91E-09 & 3.00 \\
\hline
\end{tabular}


TABLE 4.5

Local-structure-preserving $L D G$ solutions and the standard $L D G$ solutions for the singular example $u(x, y)=r^{\alpha} \sin (\alpha \theta)$, where $(r, \theta)$ is the polar coordinate and $\alpha=4 / 3 . C_{11}=10 . h_{0}=0.1$.

\begin{tabular}{|c|c|c|c|c|c|c|}
\hline meshsize $h$ & $\left\|e_{u}\right\|_{0}$ & rate & $\left\|\mathbf{e}_{\mathbf{q}}\right\|_{0}$ & rate & $\left(\mathbf{e}_{\mathbf{q}}, \mathbf{e}_{\mathbf{u}}\right) \|_{\mathcal{A}}$ & rate \\
\hline \multicolumn{7}{|c|}{$P^{1}-\mathrm{LSP}$} \\
\hline$h_{0}$ & $5.72 \mathrm{E}-04$ & - & $8.36 \mathrm{E}-03$ & - & $2.46 \mathrm{E}-02$ & - \\
\hline$h_{0} / 2$ & $1.47 \mathrm{E}-04$ & 1.96 & $3.21 \mathrm{E}-03$ & 1.38 & $9.13 \mathrm{E}-03$ & 1.43 \\
\hline$h_{0} / 4$ & $3.78 \mathrm{E}-05$ & 1.97 & $1.24 \mathrm{E}-03$ & 1.37 & $3.35 \mathrm{E}-03$ & 1.45 \\
\hline$h_{0} / 8$ & $9.62 \mathrm{E}-06$ & 1.97 & $4.81 \mathrm{E}-04$ & 1.36 & $1.22 \mathrm{E}-03$ & 1.46 \\
\hline$h_{0} / 16$ & $2.45 \mathrm{E}-06$ & 1.98 & $1.88 \mathrm{E}-04$ & 1.35 & $4.43 \mathrm{E}-04$ & 1.46 \\
\hline$h_{0} / 32$ & $6.23 \mathrm{E}-07$ & 1.97 & 7.44E-05 & 1.34 & $1.62 \mathrm{E}-04$ & 1.46 \\
\hline \multicolumn{7}{|c|}{$P^{1}-$ Std } \\
\hline$h_{0}$ & $5.73 \mathrm{E}-04$ & & $8.46 \mathrm{E}-03$ & - & $2.47 \mathrm{E}-02$ & - \\
\hline$h_{0} / 2$ & $1.47 \mathrm{E}-04$ & 1.96 & $3.28 \mathrm{E}-03$ & 1.37 & $9.15 \mathrm{E}-03$ & 1.43 \\
\hline$h_{0} / 4$ & $3.74 \mathrm{E}-05$ & 1.97 & $1.28 \mathrm{E}-03$ & 1.35 & $3.36 \mathrm{E}-03$ & 1.45 \\
\hline$h_{0} / 8$ & $9.47 \mathrm{E}-06$ & 1.98 & $5.06 \mathrm{E}-04$ & 1.34 & $1.23 \mathrm{E}-03$ & 1.45 \\
\hline$h_{0} / 16$ & $2.38 \mathrm{E}-06$ & 1.99 & $2.01 \mathrm{E}-04$ & 1.33 & $4.47 \mathrm{E}-04$ & 1.46 \\
\hline$h_{0} / 32$ & $5.98 \mathrm{E}-07$ & 1.99 & $8.00 \mathrm{E}-05$ & 1.33 & 1.63E-04 & 1.46 \\
\hline \multicolumn{7}{|c|}{ P' } \\
\hline$h_{0}$ & $5.30 \mathrm{E}-05$ & - & $2.35 \mathrm{E}-03$ & - & $2.83 \mathrm{E}-03$ & - \\
\hline$h_{0} / 2$ & $1.06 \mathrm{E}-05$ & 2.33 & $9.32 \mathrm{E}-04$ & 1.33 & $1.12 \mathrm{E}-03$ & 1.33 \\
\hline$h_{0} / 4$ & $2.10 \mathrm{E}-06$ & 2.33 & $3.70 \mathrm{E}-04$ & 1.33 & $4.46 \mathrm{E}-04$ & 1.33 \\
\hline$h_{0} / 8$ & $4.17 \mathrm{E}-07$ & 2.33 & $1.47 \mathrm{E}-04$ & 1.33 & $1.77 \mathrm{E}-04$ & 1.33 \\
\hline$h_{0} / 16$ & $8.27 \mathrm{E}-08$ & 2.33 & $5.83 \mathrm{E}-05$ & 1.33 & $7.03 \mathrm{E}-05$ & 1.33 \\
\hline$h_{0} / 32$ & $1.64 \mathrm{E}-08$ & 2.33 & $2.31 \mathrm{E}-05$ & 1.33 & $2.79 \mathrm{E}-05$ & 1.33 \\
\hline \multicolumn{7}{|c|}{$P^{2}$-Std } \\
\hline$h_{0}$ & $4.57 \mathrm{E}-05$ & - & $2.46 \mathrm{E}-03$ & - & $2.89 \mathrm{E}-03$ & - \\
\hline$h_{0} / 2$ & $9.10 \mathrm{E}-06$ & 2.33 & $9.76 \mathrm{E}-04$ & 1.33 & $1.15 \mathrm{E}-03$ & 1.33 \\
\hline$h_{0} / 4$ & $1.81 \mathrm{E}-06$ & 2.33 & $3.88 \mathrm{E}-04$ & 1.33 & $4.56 \mathrm{E}-04$ & 1.33 \\
\hline$h_{0} / 8$ & $3.59 \mathrm{E}-07$ & 2.33 & $1.54 \mathrm{E}-04$ & 1.33 & $1.81 \mathrm{E}-04$ & 1.33 \\
\hline$h_{0} / 16$ & $7.12 \mathrm{E}-08$ & 2.33 & $6.11 \mathrm{E}-05$ & 1.33 & $7.18 \mathrm{E}-05$ & 1.33 \\
\hline$h_{0} / 32$ & $1.41 \mathrm{E}-08$ & 2.33 & $2.42 \mathrm{E}-05$ & 1.33 & $2.85 \mathrm{E}-05$ & 1.33 \\
\hline \multicolumn{7}{|c|}{ 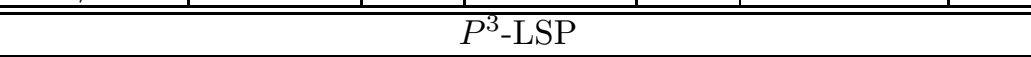 } \\
\hline$h_{0}$ & $1.98 \mathrm{E}-05$ & - & $1.62 \mathrm{E}-03$ & - & $1.73 \mathrm{E}-03$ & - \\
\hline$h_{0} / 2$ & $4.23 \mathrm{E}-06$ & 2.23 & $6.34 \mathrm{E}-04$ & 1.36 & $6.58 \mathrm{E}-04$ & 1.39 \\
\hline$h_{0} / 4$ & $9.01 \mathrm{E}-07$ & 2.23 & $2.48 \mathrm{E}-04$ & 1.35 & $2.54 \mathrm{E}-04$ & 1.37 \\
\hline$h_{0} / 8$ & $1.89 \mathrm{E}-07$ & 2.25 & $9.78 \mathrm{E}-05$ & 1.35 & $9.90 \mathrm{E}-05$ & 1.36 \\
\hline$h_{0} / 16$ & 3.91E-08 & 2.27 & $3.86 \mathrm{E}-05$ & 1.34 & $3.89 \mathrm{E}-05$ & 1.35 \\
\hline \multicolumn{7}{|c|}{$P^{3}-$ Std } \\
\hline$h_{0}$ & $1.40 \mathrm{E}-05$ & - & $1.60 \mathrm{E}-03$ & - & $1.67 \mathrm{E}-03$ & - \\
\hline$h_{0} / 2$ & $2.77 \mathrm{E}-06$ & 2.33 & $6.35 \mathrm{E}-04$ & 1.33 & $6.64 \mathrm{E}-04$ & 1.33 \\
\hline$h_{0} / 4$ & $5.50 \mathrm{E}-07$ & 2.33 & $2.52 \mathrm{E}-04$ & 1.33 & $2.64 \mathrm{E}-04$ & 1.33 \\
\hline$h_{0} / 8$ & 1.09E-07 & 2.33 & $1.00 \mathrm{E}-04$ & 1.33 & $1.05 \mathrm{E}-04$ & 1.33 \\
\hline$h_{0} / 16$ & $2.16 \mathrm{E}-08$ & 2.33 & $3.97 \mathrm{E}-05$ & 1.33 & $4.15 \mathrm{E}-05$ & 1.33 \\
\hline
\end{tabular}


TABLE 4.6

Local-structure-preserving $L D G$ solutions and the standard $L D G$ solutions for the singular example $u(x, y)=r^{\alpha} \sin (\alpha \theta)$, where $(r, \theta)$ is the polar coordinate and $\alpha=4 / 3 . C_{11}=1 / h . h_{0}=0.1$.

\begin{tabular}{|c|c|c|c|c|c|c|}
\hline meshsize $h$ & $\left\|e_{u}\right\|_{0}$ & rate & $\left\|\mathbf{e}_{\mathbf{q}}\right\|_{0}$ & rate & $\left(\mathbf{e}_{\mathbf{q}}, \mathbf{e}_{\mathbf{u}}\right) \|_{\mathcal{A}}$ & rate \\
\hline \multicolumn{7}{|c|}{$P^{1}-\mathrm{LSP}$} \\
\hline$h_{0}$ & $5.72 \mathrm{E}-04$ & - & $8.36 \mathrm{E}-03$ & - & $2.46 \mathrm{E}-02$ & - \\
\hline$h_{0} / 2$ & $1.46 \mathrm{E}-04$ & 1.97 & $3.54 \mathrm{E}-03$ & 1.24 & $1.25 \mathrm{E}-02$ & 0.98 \\
\hline$h_{0} / 4$ & $3.70 \mathrm{E}-05$ & 1.98 & $1.53 \mathrm{E}-03$ & 1.21 & $6.29 \mathrm{E}-03$ & 0.99 \\
\hline$h_{0} / 8$ & $9.35 \mathrm{E}-06$ & 1.98 & $6.77 \mathrm{E}-04$ & 1.18 & $3.16 \mathrm{E}-03$ & 0.99 \\
\hline$h_{0} / 16$ & $2.36 \mathrm{E}-06$ & 1.99 & $3.08 \mathrm{E}-04$ & 1.14 & $1.59 \mathrm{E}-03$ & 0.99 \\
\hline$h_{0} / 32$ & $5.92 \mathrm{E}-07$ & 1.99 & $1.43 \mathrm{E}-04$ & 1.10 & $7.96 \mathrm{E}-04$ & 1.00 \\
\hline \multicolumn{7}{|c|}{$P^{1}$-Std } \\
\hline$h_{0}$ & $5.73 \mathrm{E}-04$ & - & $8.46 \mathrm{E}-03$ & - & $2.47 \mathrm{E}-02$ & - \\
\hline$h_{0} / 2$ & $1.46 \mathrm{E}-04$ & 1.97 & $3.58 \mathrm{E}-03$ & 1.21 & $1.25 \mathrm{E}-02$ & 0.98 \\
\hline$h_{0} / 4$ & $3.71 \mathrm{E}-05$ & 1.98 & $1.55 \mathrm{E}-03$ & 1.21 & $6.30 \mathrm{E}-03$ & 0.99 \\
\hline$h_{0} / 8$ & $9.37 \mathrm{E}-06$ & 1.98 & $6.84 \mathrm{E}-04$ & 1.18 & $3.17 \mathrm{E}-03$ & 0.99 \\
\hline$h_{0} / 16$ & $2.36 \mathrm{E}-06$ & 1.99 & $3.10 \mathrm{E}-04$ & 1.14 & $1.59 \mathrm{E}-03$ & 0.99 \\
\hline$h_{0} / 32$ & $5.93 \mathrm{E}-07$ & 1.99 & $1.44 \mathrm{E}-04$ & 1.11 & $7.96 \mathrm{E}-04$ & 1.00 \\
\hline \multicolumn{7}{|c|}{$P^{2}$-LSP } \\
\hline$h_{0}$ & $5.30 \mathrm{E}-05$ & - & $2.35 \mathrm{E}-03$ & - & $2.83 \mathrm{E}-03$ & - \\
\hline$h_{0} / 2$ & $1.06 \mathrm{E}-05$ & 2.33 & $9.32 \mathrm{E}-04$ & 1.33 & $1.12 \mathrm{E}-03$ & 1.33 \\
\hline$h_{0} / 4$ & $2.10 \mathrm{E}-06$ & 2.33 & $3.70 \mathrm{E}-04$ & 1.33 & $4.46 \mathrm{E}-04$ & 1.33 \\
\hline$h_{0} / 8$ & 4.17E-07 & 2.33 & $1.47 \mathrm{E}-04$ & 1.33 & $1.77 \mathrm{E}-04$ & 1.33 \\
\hline$h_{0} / 16$ & $8.27 \mathrm{E}-08$ & 2.33 & $5.83 \mathrm{E}-05$ & 1.33 & 7.03E-05 & 1.33 \\
\hline$h_{0} / 32$ & $1.64 \mathrm{E}-08$ & 2.33 & $2.31 \mathrm{E}-05$ & 1.33 & $2.79 \mathrm{E}-05$ & 1.33 \\
\hline \multicolumn{7}{|c|}{$P^{2}-$ Std } \\
\hline$h_{0}$ & $4.57 \mathrm{E}-05$ & - & $2.46 \mathrm{E}-03$ & - & $2.89 \mathrm{E}-03$ & - \\
\hline$h_{0} / 2$ & $9.36 \mathrm{E}-06$ & 2.29 & $9.58 \mathrm{E}-04$ & 1.36 & $1.06 \mathrm{E}-03$ & 1.45 \\
\hline$h_{0} / 4$ & $1.90 \mathrm{E}-06$ & 2.30 & $3.77 \mathrm{E}-04$ & 1.34 & $3.98 \mathrm{E}-04$ & 1.41 \\
\hline$h_{0} / 8$ & $3.80 \mathrm{E}-07$ & 2.32 & $1.49 \mathrm{E}-04$ & 1.34 & $1.54 \mathrm{E}-04$ & 1.37 \\
\hline$h_{0} / 16$ & $7.59 \mathrm{E}-08$ & 2.32 & $5.91 \mathrm{E}-05$ & 1.34 & $6.00 \mathrm{E}-05$ & 1.36 \\
\hline$h_{0} / 32$ & $1.51 \mathrm{E}-08$ & 2.33 & $2.35 \mathrm{E}-05$ & 1.33 & $2.36 \mathrm{E}-05$ & 1.34 \\
\hline \multicolumn{7}{|c|}{$P^{3}$-LSP } \\
\hline$h_{0}$ & $1.98 \mathrm{E}-05$ & - & $1.62 \mathrm{E}-03$ & - & $1.73 \mathrm{E}-03$ & - \\
\hline$h_{0} / 2$ & $3.93 \mathrm{E}-06$ & 2.33 & $6.44 \mathrm{E}-04$ & 1.33 & $6.87 \mathrm{E}-04$ & 1.33 \\
\hline$h_{0} / 4$ & $7.80 \mathrm{E}-07$ & 2.33 & $2.56 \mathrm{E}-04$ & 1.33 & $2.72 \mathrm{E}-04$ & 1.33 \\
\hline$h_{0} / 8$ & $1.54 \mathrm{E}-07$ & 2.33 & $1.01 \mathrm{E}-04$ & 1.33 & $1.08 \mathrm{E}-04$ & 1.33 \\
\hline$h_{0} / 16$ & 3.07E-08 & 2.33 & 4.03E-05 & 1.33 & $4.29 \mathrm{E}-05$ & 1.33 \\
\hline \multicolumn{7}{|c|}{$P^{3}-$ Std } \\
\hline$h_{0}$ & $1.40 \mathrm{E}-05$ & - & $1.60 \mathrm{E}-03$ & - & $1.67 \mathrm{E}-03$ & - \\
\hline$h_{0} / 2$ & $2.81 \mathrm{E}-06$ & 2.31 & $6.33 \mathrm{E}-04$ & 1.34 & $6.49 \mathrm{E}-04$ & 1.37 \\
\hline$h_{0} / 4$ & $5.64 \mathrm{E}-07$ & 2.32 & $2.51 \mathrm{E}-04$ & 1.34 & $2.54 \mathrm{E}-04$ & 1.35 \\
\hline$h_{0} / 8$ & $1.12 \mathrm{E}-07$ & 2.33 & $9.94 \mathrm{E}-05$ & 1.33 & $1.00 \mathrm{E}-04$ & 1.34 \\
\hline$h_{0} / 16$ & $2.24 \mathrm{E}-08$ & 2.33 & $3.95 \mathrm{E}-05$ & 1.33 & $3.96 \mathrm{E}-05$ & 1.34 \\
\hline
\end{tabular}


TABLE 4.7

Local-structure-preserving LDG solutions using $\mathbf{M}_{h}^{k}$ (LSP) or $\overline{\mathbf{M}}_{h}^{k}$ (Mix) as the space for $\mathbf{q}_{h}$. $C_{11}=10$ for the smooth example $u(x, y)=e^{-x} \cos (y) . h_{0}=0.1$.

\begin{tabular}{|c|c|c|c|c|c|c|}
\hline meshsize $h$ & $\left\|e_{u}\right\|_{0}$ & rate & $\left\|\mathbf{e}_{\mathbf{q}}\right\|_{0}$ & rate & $\left(\mathbf{e}_{\mathbf{q}}, \mathbf{e}_{\mathbf{u}}\right) \|_{\mathcal{A}}$ & rate \\
\hline \multicolumn{7}{|c|}{$P^{2}-\mathrm{LSP}$} \\
\hline$h_{0}$ & $1.20 \mathrm{E}-05$ & - & $2.89 \mathrm{E}-04$ & - & $4.71 \mathrm{E}-04$ & - \\
\hline$h_{0} / 2$ & $1.93 \mathrm{E}-06$ & 2.64 & $5.16 \mathrm{E}-05$ & 2.49 & $9.55 \mathrm{E}-05$ & 2.30 \\
\hline$h_{0} / 4$ & 2.92E-07 & 2.73 & $8.08 \mathrm{E}-06$ & 2.67 & $1.85 \mathrm{E}-05$ & 2.37 \\
\hline$h_{0} / 8$ & 4.11E-08 & 2.83 & $1.15 \mathrm{E}-06$ & 2.81 & $3.46 \mathrm{E}-06$ & 2.42 \\
\hline$h_{0} / 16$ & $5.48 \mathrm{E}-09$ & 2.90 & $1.56 \mathrm{E}-07$ & 2.89 & $6.31 \mathrm{E}-07$ & 2.46 \\
\hline$h_{0} / 32$ & 7.10E-10 & 2.95 & $2.04 \mathrm{E}-08$ & 2.93 & 1.13E-07 & 2.48 \\
\hline \multicolumn{7}{|c|}{$P^{2}$-Mix } \\
\hline$h_{0}$ & $8.58 \mathrm{E}-06$ & - & $4.73 \mathrm{E}-04$ & - & $5.55 \mathrm{E}-04$ & - \\
\hline$h_{0} / 2$ & 1.09E-06 & 2.98 & $1.23 \mathrm{E}-04$ & 1.95 & 1.33E-04 & 2.06 \\
\hline$h_{0} / 4$ & $1.37 \mathrm{E}-07$ & 2.99 & $3.13 \mathrm{E}-05$ & 1.97 & $3.26 \mathrm{E}-05$ & 2.03 \\
\hline$h_{0} / 8$ & $1.71 \mathrm{E}-08$ & 3.00 & 7.90E-06 & 1.98 & 8.07E-06 & 2.01 \\
\hline$h_{0} / 16$ & 2.14E-09 & 3.00 & $1.99 \mathrm{E}-06$ & 1.99 & $2.01 \mathrm{E}-06$ & 2.01 \\
\hline$h_{0} / 32$ & $2.68 \mathrm{E}-10$ & 3.00 & $4.98 \mathrm{E}-07$ & 2.00 & $5.01 \mathrm{E}-07$ & 2.00 \\
\hline \multicolumn{7}{|c|}{$\overline{P^{3}-\mathrm{LSP}}$} \\
\hline$h_{0}$ & $2.31 \mathrm{E}-07$ & - & $5.65 \mathrm{E}-06$ & - & $7.78 \mathrm{E}-06$ & - \\
\hline$h_{0} / 2$ & $1.74 \mathrm{E}-08$ & 3.73 & $5.33 \mathrm{E}-07$ & 3.41 & $8.10 \mathrm{E}-07$ & 3.26 \\
\hline$h_{0} / 4$ & $1.26 \mathrm{E}-09$ & 3.79 & $4.78 \mathrm{E}-08$ & 3.48 & $8.11 \mathrm{E}-08$ & 3.32 \\
\hline$h_{0} / 8$ & 8.71E-11 & 3.85 & 4.44E-09 & 3.43 & 7.97E-09 & 3.35 \\
\hline$h_{0} / 16$ & $5.57 \mathrm{E}-12$ & 3.97 & $4.50 \mathrm{E}-10$ & 3.30 & 7.85E-10 & 3.34 \\
\hline \multicolumn{7}{|c|}{$P^{3}$-Mix } \\
\hline$h_{0}$ & $1.74 \mathrm{E}-07$ & - & $8.31 \mathrm{E}-06$ & - & $9.11 \mathrm{E}-06$ & - \\
\hline$h_{0} / 2$ & $1.11 \mathrm{E}-08$ & 3.96 & $1.05 \mathrm{E}-06$ & 2.99 & $1.10 \mathrm{E}-06$ & 3.05 \\
\hline$h_{0} / 4$ & $7.06 \mathrm{E}-10$ & 3.98 & $1.32 \mathrm{E}-07$ & 2.99 & $1.35 \mathrm{E}-07$ & 3.03 \\
\hline$h_{0} / 8$ & $4.48 \mathrm{E}-11$ & 3.98 & 1.65E-08 & 3.00 & 1.67E-08 & 3.01 \\
\hline$h_{0} / 16$ & $5.19 \mathrm{E}-12$ & 3.11 & 2.06E-09 & 3.00 & $2.08 \mathrm{E}-09$ & 3.01 \\
\hline
\end{tabular}

REMARK 4.1. The condition number of the final linear system of the localstructure-preserving $L D G$ method for the Laplace equation is in the same order as the one from the standard $L D G$ method for the same equation. This is observed through our numerical experiments as the iteration numbers for convergence are comparable for these two cases.

5. Concluding remarks. By taking advantage of the flexibility of choosing solution spaces in the discontinuous Galerkin method and the local discontinuous Galerkin method, we develop a local-structure-preserving local discontinuous Galerkin method for the Laplace equation. In this method, the equation is locally satisfied exactly by the approximating solutions and these approximations perform comparably well as the standard approximations without this structure-preserving property. All these are achieved with a significantly reduced computational cost. Future work will include an $L^{2}$ error estimate, and a generalization of the method to more general PDEs such as the Poisson equation and other elliptic equations. The full elliptic regularity is assumed in the analysis in this paper for simplicity. More general cases can be analyzed with more delicate details. 
TABLE 4.8

Local-structure-preserving LDG solutions using $\mathbf{M}_{h}^{k}$ (LSP) or $\overline{\mathbf{M}}_{h}^{k}$ (Mix) as the space for $\mathbf{q}_{h}$. $C_{11}=1 / h$ for the smooth example $u(x, y)=e^{-x} \cos (y) . h_{0}=0.1$.

\begin{tabular}{|c|c|c|c|c|c|c|}
\hline meshsize $h$ & $\left\|e_{u}\right\|_{0}$ & rate & $\left\|\mathbf{e}_{\mathbf{q}}\right\|_{0}$ & rate & $\overline{\left(\mathbf{e}_{\mathbf{q}}, \mathbf{e}_{\mathbf{u}}\right) \|_{\mathcal{A}}}$ & rate \\
\hline \multicolumn{7}{|c|}{$P^{2}-\mathrm{LSP}$} \\
\hline$\overline{h_{0}}$ & $1.20 \mathrm{E}-05$ & - & $2.89 \mathrm{E}-04$ & - & $4.71 \mathrm{E}-04$ & - \\
\hline$h_{0} / 2$ & $1.53 \mathrm{E}-06$ & 2.97 & $7.51 \mathrm{E}-05$ & 1.95 & $1.20 \mathrm{E}-04$ & 1.97 \\
\hline$h_{0} / 4$ & $1.93 \mathrm{E}-07$ & 2.99 & $1.91 \mathrm{E}-05$ & 1.97 & $3.04 \mathrm{E}-05$ & 1.98 \\
\hline$h_{0} / 8$ & $2.43 \mathrm{E}-08$ & 2.99 & $4.82 \mathrm{E}-06$ & 1.99 & $7.65 \mathrm{E}-06$ & 1.99 \\
\hline$h_{0} / 16$ & $3.04 \mathrm{E}-09$ & 2.99 & $1.21 \mathrm{E}-06$ & 1.99 & $1.92 \mathrm{E}-06$ & 2.00 \\
\hline$h_{0} / 32$ & $3.81 \mathrm{E}-10$ & 3.00 & $3.03 \mathrm{E}-07$ & 2.00 & $4.80 \mathrm{E}-07$ & 2.00 \\
\hline \multicolumn{7}{|c|}{$P^{2}$-Mix } \\
\hline$h_{0}$ & $8.58 \mathrm{E}-06$ & - & $4.73 \mathrm{E}-04$ & - & $5.55 \mathrm{E}-04$ & - \\
\hline$h_{0} / 2$ & $1.06 \mathrm{E}-06$ & 3.01 & $1.24 \mathrm{E}-04$ & 1.93 & $1.43 \mathrm{E}-04$ & 1.96 \\
\hline$h_{0} / 4$ & $1.32 \mathrm{E}-07$ & 3.01 & $3.16 \mathrm{E}-05$ & 1.97 & $3.61 \mathrm{E}-05$ & 1.98 \\
\hline$h_{0} / 8$ & 1.65E-08 & 3.00 & $7.99 \mathrm{E}-06$ & 1.99 & $9.09 \mathrm{E}-06$ & 1.99 \\
\hline$h_{0} / 16$ & 2.05E-09 & 3.00 & $2.01 \mathrm{E}-06$ & 1.99 & $2.28 \mathrm{E}-06$ & 2.00 \\
\hline$h_{0} / 32$ & $2.57 \mathrm{E}-10$ & 3.00 & $5.03 \mathrm{E}-07$ & 2.00 & $5.71 \mathrm{E}-07$ & 2.00 \\
\hline \multicolumn{7}{|c|}{ 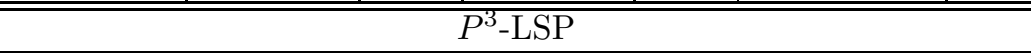 } \\
\hline$h_{0}$ & $2.31 \mathrm{E}-07$ & - & $5.65 \mathrm{E}-06$ & - & $7.78 \mathrm{E}-06$ & - \\
\hline$h_{0} / 2$ & $1.46 \mathrm{E}-08$ & 3.98 & $7.21 \mathrm{E}-07$ & 2.97 & $9.85 \mathrm{E}-07$ & 2.98 \\
\hline$h_{0} / 4$ & $9.15 \mathrm{E}-10$ & 3.99 & $9.10 \mathrm{E}-08$ & 2.99 & $1.24 \mathrm{E}-07$ & 2.99 \\
\hline$h_{0} / 8$ & $5.74 \mathrm{E}-11$ & 3.99 & $1.14 \mathrm{E}-08$ & 2.99 & $1.55 \mathrm{E}-08$ & 3.00 \\
\hline$h_{0} / 16$ & $4.11 \mathrm{E}-12$ & 3.80 & $1.43 \mathrm{E}-09$ & 3.00 & $1.94 \mathrm{E}-09$ & 3.00 \\
\hline \multicolumn{7}{|c|}{$P^{3}$-Mix } \\
\hline$h_{0}$ & $1.74 \mathrm{E}-07$ & - & $8.30 \mathrm{E}-06$ & - & $9.11 \mathrm{E}-06$ & - \\
\hline$h_{0} / 2$ & $1.09 \mathrm{E}-08$ & 3.99 & $1.06 \mathrm{E}-06$ & 2.97 & $1.15 \mathrm{E}-06$ & 2.98 \\
\hline$h_{0} / 4$ & $6.82 \mathrm{E}-10$ & 4.00 & $1.33 \mathrm{E}-07$ & 2.99 & $1.45 \mathrm{E}-07$ & 2.99 \\
\hline$h_{0} / 8$ & $4.30 \mathrm{E}-11$ & 3.99 & $1.67 \mathrm{E}-08$ & 2.99 & $1.81 \mathrm{E}-08$ & 3.00 \\
\hline$h_{0} / 16$ & $4.97 \mathrm{E}-12$ & 3.11 & 2.09E-09 & 3.00 & $2.27 \mathrm{E}-09$ & 3.00 \\
\hline
\end{tabular}

Acknowledgment. We would like to thank Bernardo Cockburn for helpful discussions.

\section{REFERENCES}

[1] G. Baker, W.N. Jureidini and O.A. Karakashian, Piecewise solenoidal vector fields and the Stokes problem, SIAM Journal on Numerical Analysis, 27 (1990), pp. 1466-1485.

[2] P. Castillo, B. Cockburn, I. Perugia And D. Schötzau, An a priori error analysis of the local discontinuous Galerkin method for elliptic problems, SIAM Journal on Numerical Analysis, 38 (2000), pp. 1676-1706.

[3] P. Ciarlet, The finite element methods for elliptic problems, North-Holland, Amsterdam, 1975.

[4] B. CockBurn, F. Li AND C.-W. Shu, Locally divergence-free discontinuous Galerkin methods for the Maxwell equations, Journal of Computational Physics, 194 (2004), pp. 588-610.

[5] B. CockBurn ANd C.-W. Shu, TVB Runge-Kutta local projection discontinuous Galerkin finite element method for conservation laws II: general framework, Mathematics of Computation, 52 (1989), pp. 411-435.

[6] B. Cockburn and C.-W. Shu, The local discontinuous Galerkin method for time-dependent convection-diffusion systems, SIAM Journal on Numerical Analysis, 35 (1998), pp. 24402463. 
[7] B. Cockburn and C.-W. Shu, Runge-Kutta Discontinuous Galerkin methods for convectiondominated problems, Journal of Scientific Computing, 16 (2001), pp. 173-261.

[8] B. Cockburn and C.-W. Shu, Foreword, special issue on discontinuous Galerkin methods, Journal of Scientific Computing, 22-23 (2005), pp. 1-3.

[9] V. Girault, P.-A. Raviart, Finite element methods for Navier-Stokes equations: theory and algorithms, Berlin ; New York: Springer-Verlag, 1986.

[10] F. Li AND C.-W. SHU, Locally divergence-free discontinuous Galerkin methods for MHD equations, Journal of Scientific Computing, 22-23 (2005), pp. 413-442.

[11] F. Li AND C.-W. SHU, Reinterpretation and simplified implementation of a discontinuous Galerkin method for Hamilton-Jacobi equations, Applied Mathematics Letters, 18 (2005), pp. 1204-1209.

[12] P. Monk, Finite element method for Maxwell's equations, Oxford Science Publications, 2003.

[13] Y. XU AND C.-W. SHu, Local discontinuous Galerkin methods for two classes of two dimensional nonlinear wave equations, Physica D, 208 (2005), pp. 21-58.

[14] J. YAn And C.-W. Shu, A local discontinuous Galerkin method for KdV type equations, SIAM Journal on Numerical Analysis, 40 (2002), pp. 769-791.

[15] J. YAN AND C.-W. ShU, Local discontinuous Galerkin methods for partial differential equations with higher order derivatives, Journal of Scientific Computing, 17 (2002), pp. 27-47. 
F. LI AND C.-W. SHU 